Review

\title{
Antibody-Directed Phototherapy (ADP)
}

\section{Hayley Pye ${ }^{1,3}$, Ioanna Stamati ${ }^{1}$, Gokhan Yahioglu ${ }^{1,2}$, M. Adil Butt ${ }^{3}$ and Mahendra Deonarain ${ }^{1,2, *}$}

1 Faculty of Natural Sciences, Imperial College London, Exhibition Road, London, SW7 2AZ, UK

2 PhotoBiotics Ltd, Montague House, Chancery Lane, Thrapston, Northamptonshire, NN14 4LN, UK

3 National Medical Laser Centre, Charles Bell House, 67-73 Riding House Street, London, W1W 7EJ, UK

* Author to whom correspondence should be addressed; E-Mail: m.deonarain@photobiotics.com.

Received: 25 February 2013; in revised form: 3 April 2013 / Accepted: 4 April 2013 /

Published: 25 April 2013

Abstract: Photodynamic therapy (PDT) is a clinically-approved but rather under-exploited treatment modality for cancer and pre-cancerous superficial lesions. It utilises a cold laser or LED to activate a photochemical reaction between a light activated drug (photosensitiser-drug) and oxygen to generate cytotoxic oxygen species. These free radical species damage cellular components leading to cell death. Despite its benefits, the complexity, limited potency and side effects of PDT have led to poor general usage. However, the research area is very active with an increasing understanding of PDT-related cell biology, photophysics and significant progress in molecular targeting of disease. Monoclonal antibody therapy is maturing and the next wave of antibody therapies includes antibody-drug conjugates (ADCs), which promise to be more potent and curable. These developments could lift antibody-directed phototherapy (ADP) to success. ADP promises to increase specificity and potency and improve drug pharmacokinetics, thus delivering better PDT drugs whilst retaining its other benefits. Whole antibody conjugates with first generation ADP-drugs displayed problems with aggregation, poor pharmacokinetics and loss of immuno-reactivity. However, these early ADP-drugs still showed improved selectivity and potency. Improved PS-drug chemistry and a variety of conjugation strategies have led to improved ADP-drugs with retained antibody and PS-drug function. More recently, recombinant antibody fragments have been used to deliver ADP-drugs with superior drug loading, more favourable pharmacokinetics, enhanced potency and target cell selectivity. These improvements offer a promise of better quality PDT drugs. 
Keywords: photodynamic; therapy; antibody targeted; photosensitiser-drug; phototherapy

\section{Introduction}

\subsection{Antibody-Drug Conjugates (ADCs)}

Antibody targeting of cancer has shown many clinical and commercial successes and continues to do so [1-5]. There are some 32 approved antibody drugs [6,7]; and over 5,000 advanced clinical trials involving antibodies [8]. The majority of these are unconjugated antibodies whose function is primarily antagonistic, neutralizing or stimulation of the immune system. However, with approaching 15 years of clinical experience of monoclonal antibodies (MAbs) as approved drugs, it is becoming apparent that antibodies, the so-called 'magic bullets' first proposed by Erlich at the turn of the 20th century, are themselves non-curative. As an example, trastuzumab (a MAb recognizing human epidermal growth factor receptor-2, (HER2); Herceptin ${ }^{\mathrm{TM}}$ ) is a successful breast cancer drug which extends survival by around 5-7 months [9]. It is thought to act via a variety of mechanisms, mainly involving modulation of oncogenic signaling pathways; however, many patients do not respond or become resistant. Patients exhibiting resistance still retain high tumour surface HER2 expression levels, resistance instead is thought to be due to subsequent changes in oncogenic signaling which circumvent the drug action [9]. This lack of HER2 receptor down-regulation has led to the development of several anti-HER2 antibody-conjugates which can continually deliver cytotoxins directly to the tumour.

Antibodies against numerous different tumour antigens have been linked to agents such as radioisotopes (radio-immunotherapy), toxins (immunotoxins) and drugs (antibody-drug conjugates, ADCs), since the 1960s and 1970s [10,11]. However the achievement of successful ADCs as clinically approved drugs has taken a long time. This issue of Antibodies will highlight the progress made in ADCs, which despite being around for over 40 years, has only one approved clinical agent (brentuximab vedotin-Adcetris ${ }^{\circledR}$ ) and one that is expected to be approved later this year (trastuzumabemansine: Herceptin-DM1). Mylotarg was approved in 2,000 for acute myeloid leukaemia but was withdrawn in June 2010 after post-approval clinical studies [11] and possibly poor sales in competition with unconjugated antibodies. Recently this has begun to change; alongside the potency 'gap' left by native antibodies now we have better characterized and validated target antigens, human-like or fully human antibodies and their recombinant fragments, improved protein-chemical conjugation technologies and more potent drugs. This has led to better-rationalized target/disease choices for ADCs with improved drug products and in the last few years we have seen the establishment of a successful class of ADC biopharmaceuticals with an exciting and growing pipeline of candidates $[11,12]$.

\subsection{Photodynamic Therapy (PDT)}

Photodynamic therapy (PDT) is a 2-step treatment for cancer and other diseases utilising a photosensitive chemical drug (a photosensitiser, PS), and its subsequent activation with an appropriate wavelength of light [13-16]. Its origins date back thousands of years where ancient Indians and Egyptians smeared leaf extracts onto skin lesions and exposed them to direct sunlight [17]. It was not 
until the early 20th century that scientists used photosensitive dyes such as acridine orange to kill microbes, or eosin to treat basal cell carcinoma, this latter work by Von Tappeiner led to the introduction of the term "photodynamic" [17,18] Since then, progression of PDT (Figure 1), has had many highlights, including the successful use of PDT in the treatment of age-related macular degeneration [15] and a number of approved PDT drugs for different cancers [19]. A list of approved and advanced-stage PDT PS-drugs is shown in Table 1. Many head \& neck cancers can be treated using PS-drugs such as Foscan ${ }^{\circledR}$ that is now championed by some in this field [20-22] over classical treatments options as it is: (i) more cost-effective; (ii) has superior cosmetic outcome with equivalent or improved results; (iii) provides the chance of a cure for patients who would otherwise have been unfit for treatment or for those who have previously failed with radiotherapy, surgery or systemic chemotherapy.

Figure 1. Historical development of Photodynamic therapy (PDT) (modified from Celli et al, [17]).

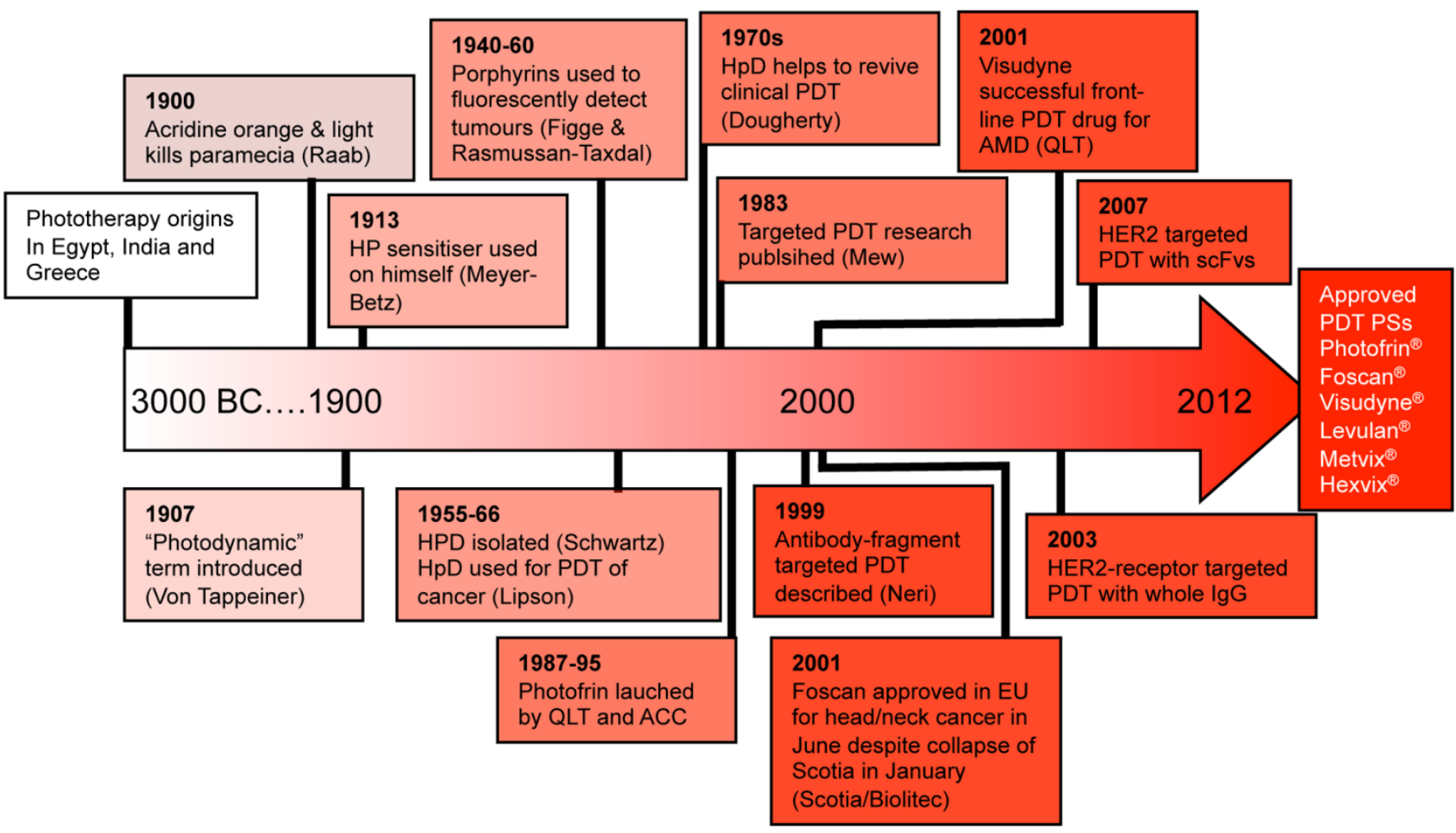

Table 1. PDT drugs. Selected clinically-advanced (B) or approved (A) PDT drugs [23].

\begin{tabular}{|c|c|c|}
\hline \multicolumn{3}{|c|}{ A: Photosensitisers approved for clinical use } \\
\hline Drug & Details & Indication \\
\hline \multirow[t]{5}{*}{$\begin{array}{l}\text { Photofrin (Porfimer } \\
\text { sodium) }\end{array}$} & \multirow{5}{*}{$\begin{array}{l}\text { A first generation PS-drug which is a mixture of } \\
\text { hematoporphyrin derivatives. Absorbs at } 630 \mathrm{~nm} \text {, so } \\
\text { limited tissue penetration }(<5 \mathrm{~mm})[24]\end{array}$} & $\begin{array}{l}\text { Oesophagus (dysplasia } \\
\text { and cancer) }\end{array}$ \\
\hline & & Stomach cancer \\
\hline & & Lung cancer \\
\hline & & Bladder cancer \\
\hline & & Cervical cancer \\
\hline Foscan (mTHPC) & $\begin{array}{l}\text { One of the most potent PS-drugs known but associated } \\
\text { with temporary pain and skin photosensitivity }[20,21]\end{array}$ & Head and neck cancer \\
\hline
\end{tabular}


Table 1. Cont.

\begin{tabular}{|c|c|c|}
\hline Drug & Details & Indication \\
\hline \multirow{3}{*}{$\begin{array}{l}\text { Levulan } \\
\text { (ALA) }\end{array}$} & \multirow{3}{*}{$\begin{array}{l}\text { A precursor compound (5-aminolevulinic acid) } \\
\text { which is taken up by cells and converted to } \\
\text { protoporphyrin IX; a potent PS-drug. Has good } \\
\text { tissue selectivity (can be } 10 \text {-fold) but the drug-light } \\
\text { interval is up to } 18 \text { h to allow for PS conversion [25]. }\end{array}$} & Basal cell carcinoma \\
\hline & & Bowens disease \\
\hline & & Actinic Keratosis \\
\hline \multirow{3}{*}{$\begin{array}{l}\text { Metvix } \\
\text { (Methyl derivative of } \\
\text { ALA) }\end{array}$} & \multirow{3}{*}{$\begin{array}{l}\text { Has reduced side effects and increased skin } \\
\text { penetration compared to 5-ALA [25] }\end{array}$} & Basal cell carcinoma \\
\hline & & Bowens disease \\
\hline & & Actinic Keratosis \\
\hline $\begin{array}{l}\text { Photosense } \\
\text { (aluminum } \\
\text { phthalocyanine) }\end{array}$ & $\begin{array}{l}\text { An aqueous solution of sodium salts of sulphonated } \\
\text { aluminum phthalocyanine. A composition of aluminion } \\
\text { phtalocyanines with different degrees of sulfonation. } \\
\text { Photosense is an relatively hydrophilic PS. }\end{array}$ & $\begin{array}{l}\text { Skin cancer } \\
\text { Oropharyngeal cancer }\end{array}$ \\
\hline $\begin{array}{l}\text { Radachlorin } \\
\text { (Bremachlorin) }\end{array}$ & $\begin{array}{l}\text { An aqueous composition of } 3 \text { chlorophyll a } \\
\text { derivatives [26] }\end{array}$ & Skin cancer \\
\hline $\begin{array}{l}\text { Laserphyrin / } \\
\text { Aptocine } \\
\text { (Talaporfin sodium) }\end{array}$ & $\begin{array}{l}\text { A water soluble photosensitizer consisting of } \\
\text { chlorin e6 and L-aspartic acid }\end{array}$ & $\begin{array}{l}\text { Lung cancer } \\
\text { (Undergoing trials in US } \\
\text { for range of solid tumours) }\end{array}$ \\
\hline $\begin{array}{l}\text { Visudyne } \\
\text { (Verteporfin) }\end{array}$ & $\begin{array}{l}\text { Almost a blockbuster drug with }>\$ 400 \mathrm{~m} \text { sales at } \\
\text { its peak in the early } 2,000 \mathrm{~s} \text {. Made up of the PS } \\
\text { benzoporphyrin derivative (BPD), has quick } \\
\text { clearance and thus a short drug-light interval } \\
\text { ( } 15 \mathrm{~min}) \text {. Absorbs at } 690 \mathrm{~nm} \text {. Ophthalmologist } \\
\text { shine the laser into the eye destroying the blood } \\
\text { vessels which are growing aberrantly over the } \\
\text { macula improving sight [15]. }\end{array}$ & $\begin{array}{l}\text { Age-related macular } \\
\text { degeneration }\end{array}$ \\
\hline \multicolumn{3}{|c|}{ B: Photosensitisers undergoing clinical trials } \\
\hline Drug & Details & Indication \\
\hline $\begin{array}{l}\text { Tookad } \\
\text { (Palladium } \\
\text { bacteriopheophorbide) }\end{array}$ & $\begin{array}{l}\text { In phase II/III clinical trials for prostate cancer. } \\
\text { A second generation PS-drug based on a palladium } \\
\text { bacteriochlorin. Demonstrates rapid blood clearance } \\
\text { and drug-light interval. It has low skin } \\
\text { photosensitivity and one of the most favourable } \\
\text { absorbance profiles of all PS-drugs }(740 \mathrm{~nm})[27,28]\end{array}$ & Prostate cancer \\
\hline $\begin{array}{l}\text { Amphinex } \\
\text { (TPCS2a) }\end{array}$ & $\begin{array}{l}\text { In Phase I/II clinical trial. First in class } \\
\text { photosensitiser using photochemical internalisation } \\
\text { of bleomycin [29] }\end{array}$ & Head and neck cancers \\
\hline $\begin{array}{l}\text { Lu-Tex } \\
\text { (Motexafin lutetium) }\end{array}$ & A tripyrrolic porphyrin which absorbs at $732 \mathrm{~nm}[30]$ & $\begin{array}{l}\text { Breast cancer } \\
\text { Prostate cancer } \\
\text { Skin cancer } \\
\end{array}$ \\
\hline $\begin{array}{l}\text { Photochlor } \\
\text { (HPPH) }\end{array}$ & $\begin{array}{l}\text { A lipophilic, chlorin derivative which absorbs at } \\
665 \mathrm{~nm}[23]\end{array}$ & $\begin{array}{l}\text { Oesophageal cancer } \\
\text { Lung cancer } \\
\text { Laryngeal cancer } \\
\text { Oropharyngeal (dysplasia } \\
\text { and cancer) } \\
\text { Basal cell carcinoma } \\
\end{array}$ \\
\hline
\end{tabular}


Despite these successes overall clinical uptake of PDT has been slow. This is due to a number of reasons which most likely include a lack of clinical acceptance of these seemingly complex drugs, low levels of randomised clinical trials and insufficient communication and understanding between healthcare professionals. Still, PDT is slowly progressing towards its establishment as a mainstream therapy in a number of disease areas rather than a niche application championed by centres and individuals. PDT has a wide spectrum of potential applications; current clinical indications for PDT that have been approved or are in active clinical trials include; treatment of solid tumours, dysplasias, papillomas, rheumatoid arthritis, age-related macular degeneration, actinic keratosis, cosmetic application, psoriasis, endometrial ablation, localized infection, coronary atherosclerosis and prophylaxis of arterial restenosis. In addition PDT also has significant scope in diagnostic and prognostic imaging or as a sterilization/ antimicrobial agent for synthetic materials or donated human samples [17,31-37].

PDT has many inherent benefits (listed in Table 2); amongst others, its selectivity can be clinician controlled by its activation by directed laser light, it is not immunosuppressive, is minimally invasive, and the inactive drug has low systemic toxicity. However PDT has been limited by a complexity in prescribing patient dosimetry and skin photosensitivity due to poor inherent selectivity and prolonged clearance rates of free PS (limitations also listed in Table 2) [38,39].

Table 2. Advantages and disadvantages of PDT [35,38,39].

\begin{tabular}{|c|c|}
\hline Advantage & Reason \\
\hline Low/non invasive & $\begin{array}{l}\text { Intravenously or topically administered drug, followed by surface or } \\
\text { endoscope/hollow needle illumination avoids the need for surgery. }\end{array}$ \\
\hline $\begin{array}{l}\text { Precise surgical tool / Low } \\
\text { scarring }\end{array}$ & $\begin{array}{l}\text { Dual specify of preferential tumour localisation and laser directionality. Lower } \\
\text { energy radiation and precise generation of cytotoxin prevents collateral } \\
\text { damage to structural and neighbouring tissues. }\end{array}$ \\
\hline Low side effects & $\begin{array}{l}\text { Low systemic toxicity of the drug in its inactive form. Light activation at the } \\
\text { sight of disease and local biological effect prevents other tissues being } \\
\text { damaged. }\end{array}$ \\
\hline $\begin{array}{l}\text { Compatible with other } \\
\text { modalities }\end{array}$ & $\begin{array}{l}\text { The PDT mechanism of action does not interfere with other established } \\
\text { treatments including chemotherapy or immunotherapy. }\end{array}$ \\
\hline $\begin{array}{l}\text { Low risk of resistance/ } \\
\text { Repeatable }\end{array}$ & $\begin{array}{l}\text { The nature of ROS and its generation in multiple cellular compartments } \\
\text { reduces the likelihood of tumour up regulation of alternative circumventive } \\
\text { pathways. Hence multiple drug doses or illumination doses can be carried out. }\end{array}$ \\
\hline Short treatment times & In the clinic, PDT requires short admittance times \\
\hline Cost effective & $\begin{array}{l}\text { PDT treatment can cost less than surgery and conventional chemotherapy } \\
\text { financially and life-years saved }\end{array}$ \\
\hline Not immunosuppressive & $\begin{array}{l}\text { Much lower chance of any immunosuppression than many other comparable } \\
\text { treatment modalities for cancer. Conversely in many cases immune-activation } \\
\text { mechanisms post PDT can lead to enhanced tumour eradication, or the } \\
\text { development of a tumour vaccine response. }\end{array}$ \\
\hline Disadvantage & Reason \\
\hline $\begin{array}{l}\text { Poor selectivity / Skin } \\
\text { photosensitivity }\end{array}$ & $\begin{array}{l}\text { Although many PS exhibit significant tumour localization, PDT drugs do not } \\
\text { have a high selectivity, in part due to their high hydrophobicity. Many PS- } \\
\text { drugs remain in the body for weeks and accumulate in the skin; patients have } \\
\text { to stay out of direct sunlight to prevent skin damage/ inflammation. This is } \\
\text { being addressed by the development of specifically targeted PS, like in ADP. }\end{array}$ \\
\hline
\end{tabular}


Table 2. Cont.

\begin{tabular}{|l|l|}
\hline Disdvantage & Reason \\
\hline Lack of approved drugs & $\begin{array}{l}\text { Clinical development of new drugs is hindered by poor understanding and/or } \\
\text { an unwillingness of pharmaceutical companies to explore the area. } \\
\text { Complicated dosimetry and a requirement for equipped PDT centres has led to } \\
\text { a lack of robust, randomized clinical trials. }\end{array}$ \\
\hline $\begin{array}{l}\text { Limited light penetration } \\
\text { into tissues }\end{array}$ & $\begin{array}{l}\text { Light propagation through tissues is heavily limited by refraction, reflection } \\
\text { and scattering processes and the absorption patterns of tissue chromophores. } \\
\text { This is being addressed by the continual improvement of laser and light } \\
\text { delivery technology including interstitial PDT under image guidance, light } \\
\text { diffusing fibres and use of red-absorbing drugs [40] }\end{array}$ \\
\hline $\begin{array}{l}\text { Not being as immediately } \\
\text { applicable to systemic } \\
\text { diseases }\end{array}$ & $\begin{array}{l}\text { PDT is not as immediately applicable to systemic/disseminated disease This is } \\
\text { being addressed by the development of the specific targeting of PS, like in } \\
\text { ADP, and the development and further understanding of PDT-induced immune } \\
\text { responses in particular antitumor-specific immunity [41] }\end{array}$ \\
\hline $\begin{array}{l}\text { A degree of oxygen } \\
\text { dependence }\end{array}$ & $\begin{array}{l}\text { Many of the effective mechanisms of PDT depend on the availability of } \\
\text { molecular oxygen in the target tissue during light irradiation. This is being } \\
\text { addressed as some PS can preferentially initiate oxygen independent } \\
\text { pathways, and light-dose fractionation can allow time for tissue re- } \\
\text { oxygenation [42] }\end{array}$ \\
\hline Difficult patient dosimetry & $\begin{array}{l}\text { Due to the range of different PS available, its multiple applications and } \\
\text { multiple factors involved in its administration, there are difficulties in } \\
\text { prescribing the correct patient dosimetry for each situation. Over-illumination } \\
\text { of some drugs can lead to drug inactivation (photobleaching). }\end{array}$ \\
\hline
\end{tabular}

\subsection{Antibody-Directed Phototherapy (ADP)}

Many academic and industrial researchers including ourselves, are developing 'Antibody-Directed Phototherapy (ADP)'. ADP is a form of ADC technology utilising antibody conjugation to deliver photosensitisers (PS) to the tumour via tumour-associated cell receptors (Figure 2). Targeting improves both specificity and efficiency, and overcomes some of the current limitations of nontargeted PDT. Antibody-targeted PDT was first proposed in the early 80s, and the influence of improvements in the ADC field is leading to more promising ADP-drugs. This review will discuss PDT in more depth, describe the progress over the years in targeted PDT (referred here as ADP) and look ahead to the future, primarily for cancer treatment. It is in cancer therapy that next-generation ADP drugs with improved biological and photo-physical characteristics are emerging.

The advantages seen with PDT over other treatments, (listed in Table 2) are also applicable to ADP when compared to ADCs. For example with laser activation, ADP allows cytotoxicity of the drug in the tumour only, sparing side effects in surrounding normal tissues, including those in which the target is expressed. On-target toxicity is often a major drug development issue. Additionally, when compared to ADCs that contain well established chemotherapy drugs, ADP is not immuno-suppressive as it does not have a preference for rapidly-dividing cells, and less likely to induce treatment induced resistance as tumours are less able to upregulate alternative, circumventive pathways often seen with chemotherapy. 
Figure 2. Schematic diagram illustrating non-targeted and targeted PDT. After extravasation from the vasculature system PS-drugs pass from the blood into the tumour microenvironment where depending on their physical properties and to what (if anything) they are attached, they can either diffuse into local cells or remain in the extracellular/cell surface environment. Particularly hydrophobic PS may be able to cross cellular membranes directly along their concentration gradient, PS-drugs that have associated with lipidbinding proteins such as LDLs (low-density lipoprotein) or HSA (human serum albumin) can get taken up piggyback or specifically via cell surface receptors. ADP refines this receptor delivery by using antibodies to deliver PS-drugs to cell-surface markers overexpressed on tumour cells; these can then specifically induce ADP-drug internalisation or not depending on the character of the targeted antigen. Either inside the cell or in the extracellular space, once exposed to light the PS-drug created singlet oxygen and other ROS which mediates cellular destruction.

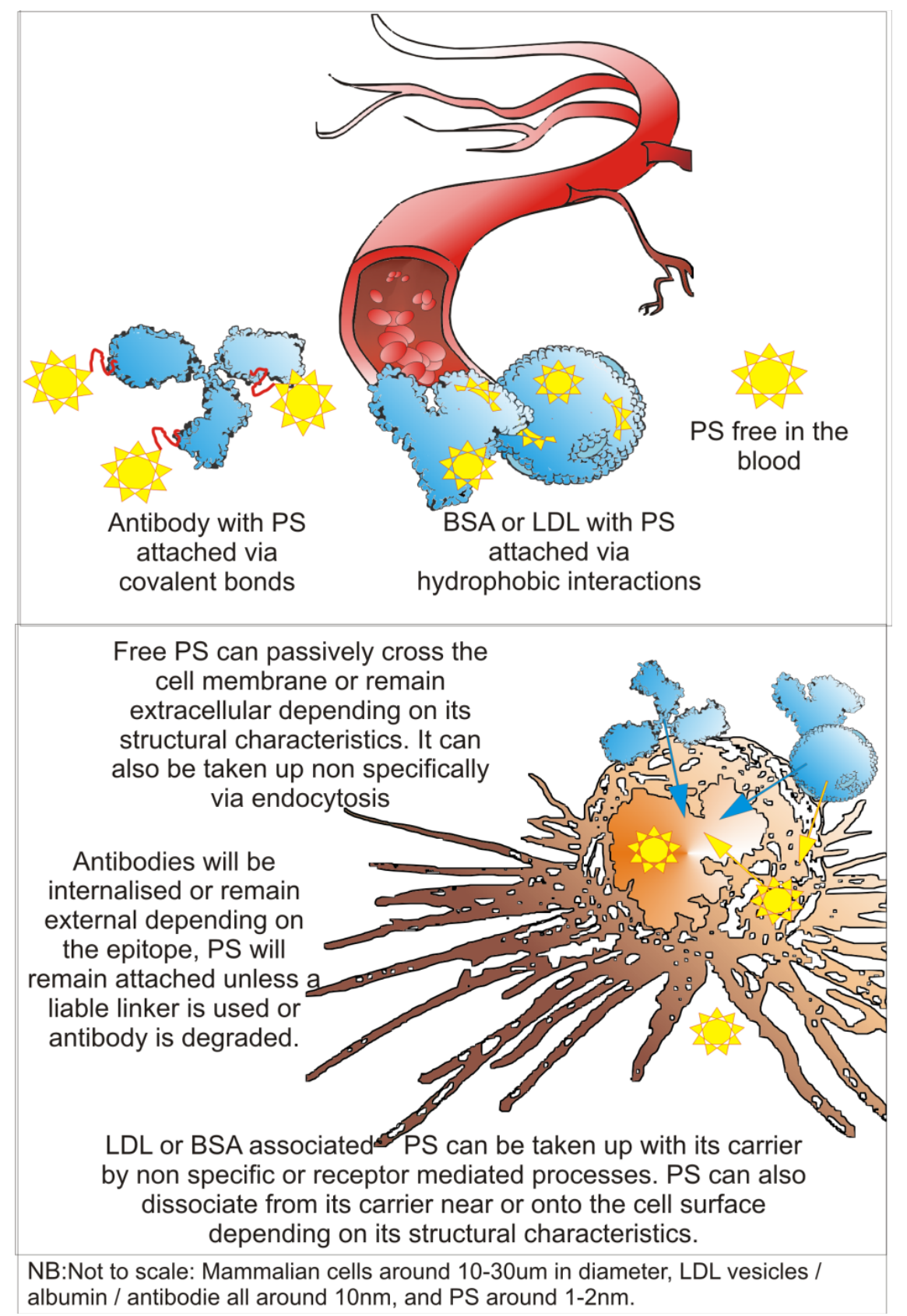




\section{Photodynamic Therapy (PDT)}

\subsection{PS-Drug Development}

Table 1 shows a list of approved PDT drugs. First generation photosensitsers were originally derived from natural substances; the first photosensitiser to achieve regulatory approval in 1993 was hematoporphyrin derivative or HPD, an extract of haemoglobin. A partial purification from HPD, Photofrin $^{\mathrm{TM}}$ is still one of the most commonly used and studied photosensitisers. However, research and application have been hindered by batch to batch variability of porphyrin oligomers of varying lengths, linkages and stereo-chemistries. Purer second generation photosensitisers were subsequently developed alongside an improvement in chemical syntheses techniques and many are currently in clinical use. These PS are mostly based on porphyrins, chlorins or bacteriochlorins, with their pharmacokinetic, photodynamic and spectral properties varying due to differences in their chemical structures (Figure 3). Any selectivity of these drugs for the target tumour, is attributed to a combination of drug hydrophobicity and the tumour microenvironment. Tumours have a tendency towards unstructured and leaky vasculature with poor lymphatic drainage [43], and a high demand for cholesterol contained within low-density lipoproteins (with which PS are frequently shown to associate) for rapid cell turnover [44].

Figure 3. Structures and spectral properties of example PS-drugs. UV/Vis absorption spectra and structures of a basic porphyrin, chlorin and bacteriochlorin. Peaks labelled A shows the Soret band, a characteristic strong absorption peak around $400 \mathrm{~nm}$. A set of 4 bands in the region of 500-800 $\mathrm{nm}$ are called the $\mathrm{Q}$ bands and are labelled $\mathrm{B}$. The reduction of a double bond in the central tetrapyrolle ring as the transition from a porphyrin to a chlorin and to the bacteriochlorin occurs causes a red shift in absorption in the Q band region [18]. Taken and modified from [45].

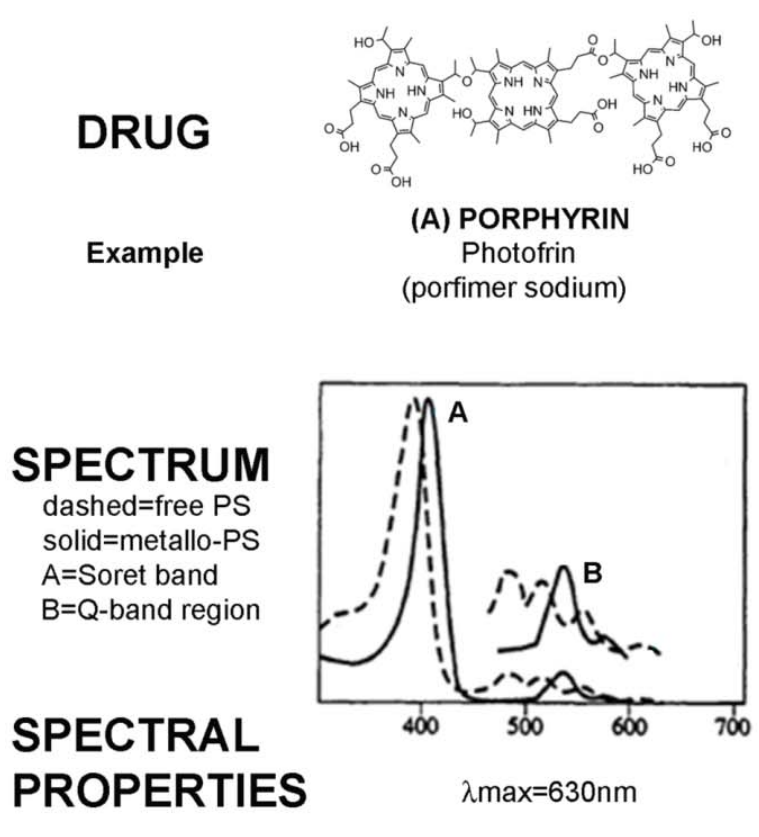

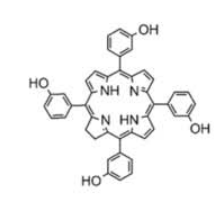

(B) CHLORIN Foscan (meta-tetra hydroxyphenyl chlorin)
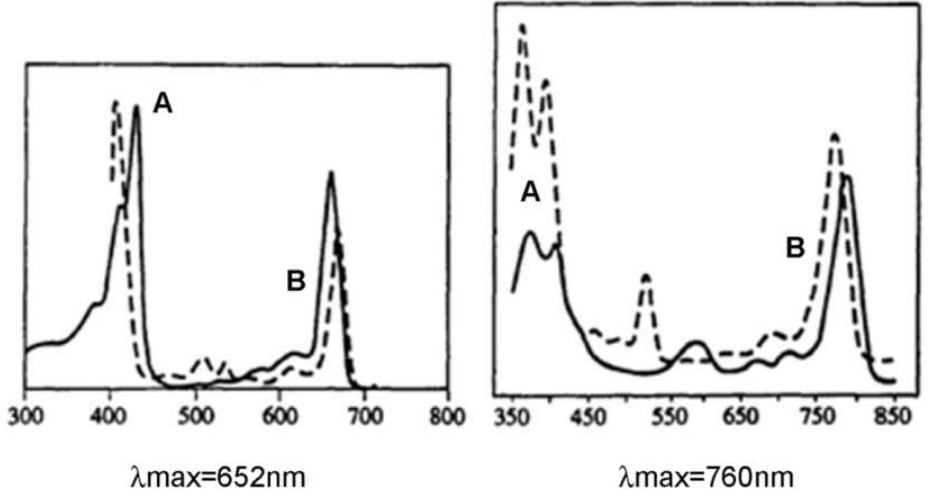
The new generation of PS-drugs, sometimes referred to as third generation, have specific features or chemical considerations making them more compatible with bioconjugation (see Section 3). This parallels recent advanced ADCs which were driven by improved drug-linkers from various synthetic chemistry innovations. Here, we will focus on antibodies as targeting agents, but the targeting concept for PS has also been explored through other ligands including peptides, small molecules, sugars and enzyme substrates utilising both active and passive targeting mechanisms [46-49].

\subsection{PDT Mechanisms}

Currently in PDT, a PS-drug is administered to the patient which endogenously localises with low/moderate selectivity in the target tissue. A cold laser or alternative light source is then used to illuminate the area to trigger a photochemical reaction (Figure 4). The PS-drug is transiently transformed into its active 'triplet state' which can react both with cellular components directly (type I processes), or indirectly via molecular oxygen which converts to active singlet oxygen (type II processes). Both these processes can initiate cytotoxic reactive oxygen species (ROS) pathways [50,51]. Due to the highly reactive nature of ROS, its lifetime within the cell is transient (unlike non-photodynamic drugs), and subsequent diffusion distance within the cell is directly related to its reactivity (Figure 4). With singlet oxygen, estimates suggest a maximal diffusion of 10-20 nm within the cellular cytoplasm [52,53], a typical whole cell diameter being 10-20 $\mu \mathrm{m}$. The action of the ROS is therefore generally restricted to the site of generation, which accounts for the low side-effects and collateral damage of PDT (when compared to chemotherapy and radiotherapy). The mechanism of PDT also lacks a single specific cellular target. Instead, it has multiple points of biological effect, thereby lowering the incidence of drug resistance from repeated treatments and overcoming the inherent variability of tumours. Intracellular activation can damage various intracellular targets, including key cellular organelles such as mitochondria, nuclear DNA and or other key membranes structures. Extracellular activation can damage the cell-surface membrane and key surface proteins therein $[54,55]$.

PDT has been shown to be able to induce cell death via a number of different routes. The three main modalities-Apoptosis, necrosis and autophagy have all been linked to PDT. Control over cell death is dependent on many aspects of PDT, but the intracellular localisation of the PS is critical in determining the type of cell damage initiated. Subcellular localization of a PS can be influenced by a number of factors including: (i) the chemical nature of the PS (inc size, lipophilicity, amphiphilic character, ionic charge, structural symmetry); (ii) serum concentration of the PS and macromolecule binding characteristics (inc protein albumin, LDL); (iii) local tissue physiology; (iv) incubation time or time after injection of PS; (v) phenotype of the target cell including the state of lipid bilayer (i.e., presence of cholesterol).

This can make it hard to compare data, but there are some good reviews on the relationship between PS structure and localisation [56-58]. Other factors that can influence cell death mechanisms include the level of internalised PS, its physicochemical properties under specific microenvironments, clinical application of light fluence/wavelength, timing of light delivery and various biological parameters of the tissue itself. The process of intracellular signalling after PDT is also complex but much work has been published on the subject. A review from tabulated major molecular events during apoptotic death induced by PDT [59], contained 181 references, covering 20 different 'major' cellular events, and this 
was selective. Large studies looking at proteome changes post PDT highlight the scale and number of pathways involved [60,61]. Pathways that are commonly manipulated by PDT alongside apoptosis, necrosis and autophagy, include the unfolded protein response, calcium homeostasis, lipid metabolism/ceramide signalling, transcriptional regulation including NF- $\kappa \mathrm{B}$ signalling, tyrosine kinase signalling including mitogen-activated protein kinases (MAPK), Cyclin-dependent kinases (CDK) and cell cycle control, heat shock protein expression, ROS and antioxidant pathways, hypoxia induced pathways and DNA-damage associated signalling. Numerous in-depth reviews have been written on this subject [55,62-64].

Figure 4. Photophysical PS mechanisms. (A) A Simplified Jablonski diagram showing the energy transfers involved in PDT. $\mathrm{S}^{0}$ is the PS-drug ground state, $\mathrm{S}^{1}$ is the PS-drug in an unstable excited state, $\mathrm{T}^{1}$ is the PS-drug's triplet excited state which can react with either molecular ground state oxygen $\left({ }^{3} \Sigma_{\mathrm{g}}\right)$ to produce singlet oxygen $\left({ }^{1} \Delta_{\mathrm{g}}\right)$ (type II reaction) or react with other substrates (type I reaction). hv denotes photon/ energy; abs: absorption; fl: fluorescence; ic: internal conversion; ph: phosphorescence; isc: intersystem crossing [35,50]. (B) Schematic comparison of the reactivity, lifetime and diffusion distance of the main cytotoxic species in PDT. Reproduced from [51-53].

(a)

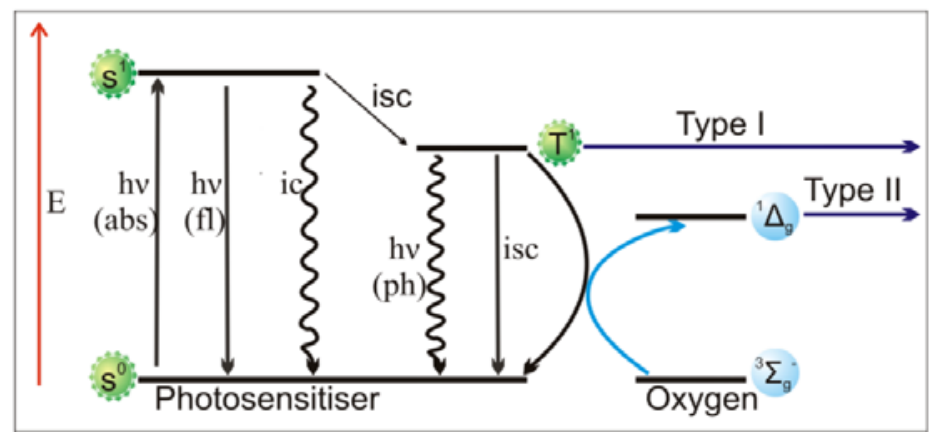

(b)

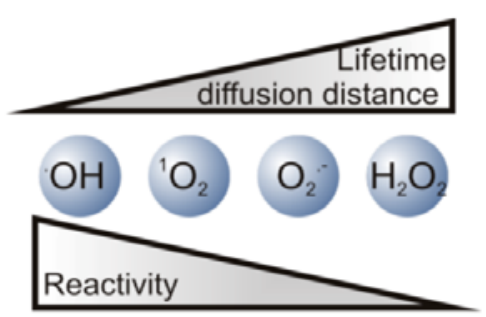

Extracellular signalling processes also effect cell survival via the direct effect of PDT, or via a secondary response in the activation of neighbouring cells and tissues. These include the effect of PDT on the extracellular matrix, the immune system, surrounding vasculature, cell adhesion, cytokine expression and angiogenesis $[41,44,63,65]$. As well as intra- and extracellular considerations, there are various other pharmacokinetic and clinical factors that can influence PDT outcome. The main factors in each of these areas are listed in (Figure 5).

When considered broadly on a clinical scale PDT can be thought to lead to a therapeutic outcome in three main ways (Figure 6). (1) Direct PDT action on target cells leads to their destruction; (2) Direct PDT action on diseased vasculature leads to their destruction and indirectly kills the tissue being supported (such as tumours); (3) Inflammatory responses generated by PDT can provoke an immune response which can lead to the destruction of disseminated tumour cells and long term immunity.

The last mechanism is particularly noteworthy as it suggests PDT, traditionally thought to act only locally, also has the potential for treating tumour metastases [66-68]. 
Figure 5. Factors influencing PDT $[43,44,57,63,69-73]$.

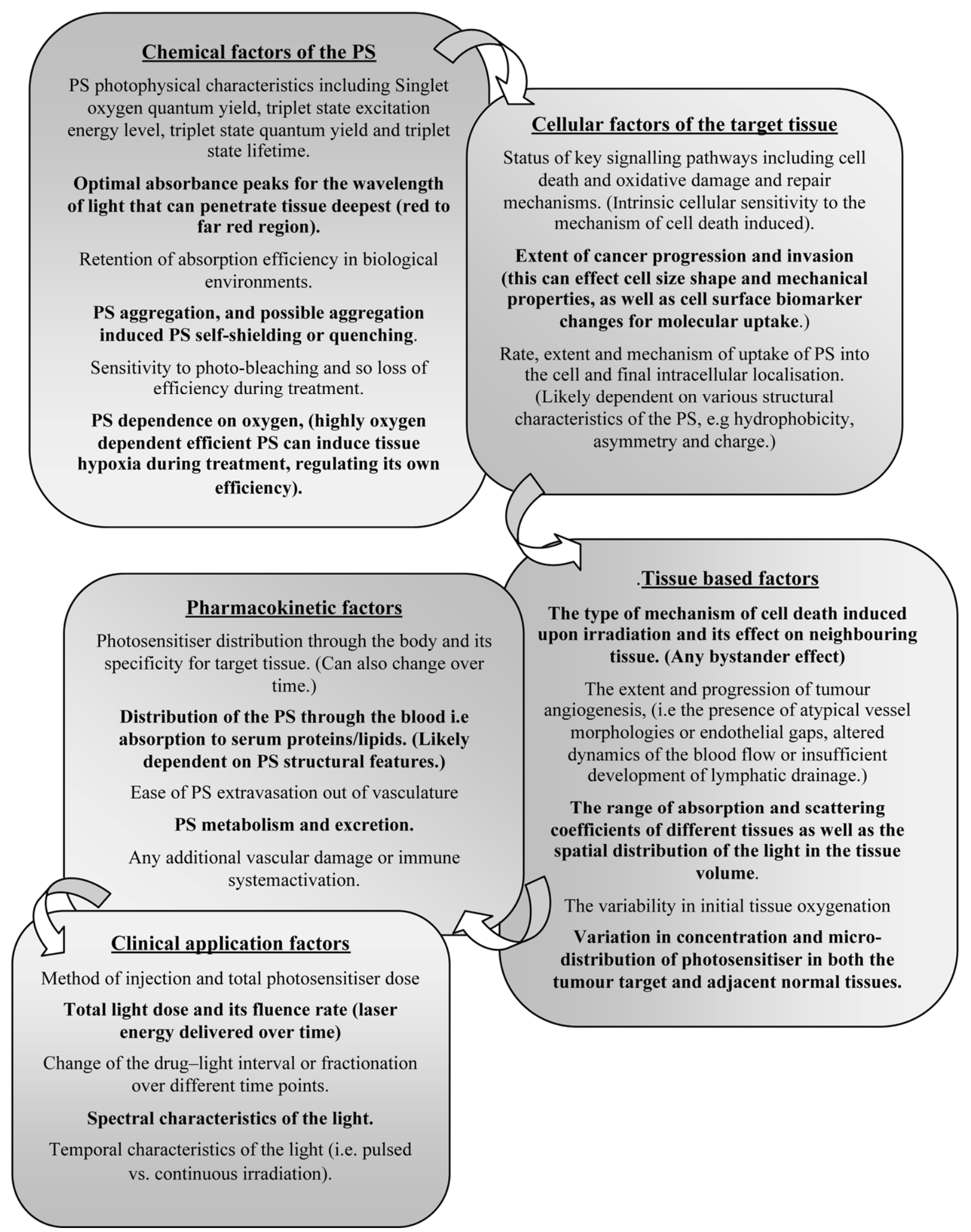


Figure 6. PDT therapeutic effects. Tumour destruction can occur through three different routes: directly on cells, indirectly via the vasculature and even further indirectly via host immune responses which can be long term and possibly anti-metastatic. Adapted from $[54,66,74]$.

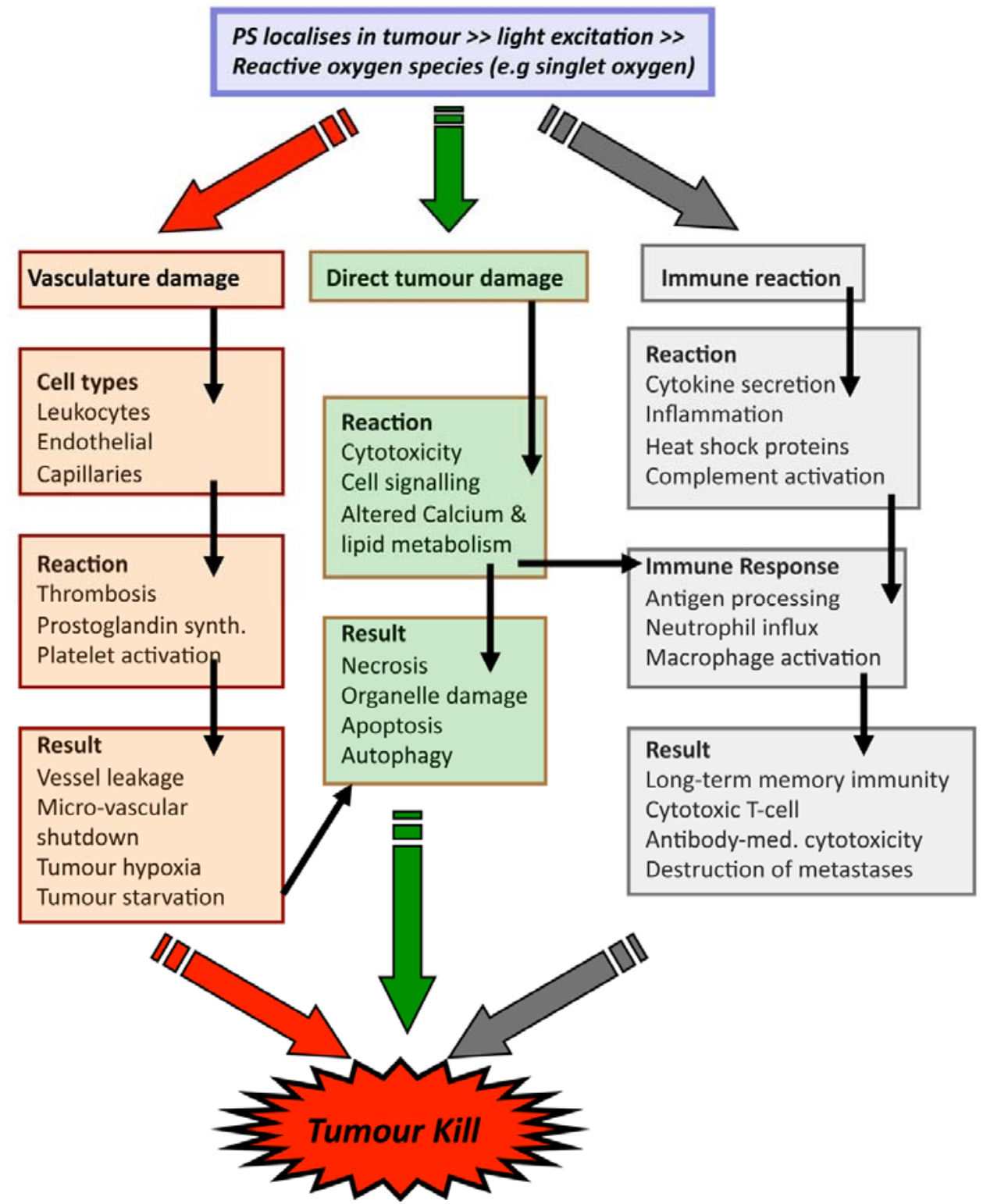

One of the main requirements in the application of PDT is the need for a light source. Light technology has made significant advances [40] with tunable, inexpensive and portable diode lasers now commonplace. Light can be delivered to target tissues wherever a light guide can be inserted. Hollow organs such as bladder and oesophagus may be illuminated via endoscope or catheter delivered fibre-optics, and solid tumours such as the pancreas, prostate or head and neck cancers can be illuminated by 'interstitial' PDT using needles inserted into various depths of the tumour $[20,27,40,75]$.

Clinical dosimetry of PDT can be manipulated to produce different effective outcomes. This may be in terms of the cell death mechanism initiated, type of tissue affected, level of oxygen consumption and the possibility of immune stimulation. These complexities, outside conventional drug therapy, may explain PDTs poor acceptance or understanding in the clinic. ADP approaches aims to reduce these complexities. 


\section{Technical Aspects of Antibody-Directed Phototherapy (ADP)}

\subsection{ADP Requirements}

An ADP-drug is made up of an antibody (of any format), a PS-drug and a linker that connects the two (which can also add some sort of functionality). ADP drugs as a result needs to exhibit physical-, chemical- and photo-stability and have drug-like properties such as scalable production, marketable storage and good shelf life. The antibody portion of the ADP-drug could also have well-defined effector functions. The resulting ADP-drug is characterised by the number of PS-drug molecules covalently attached per antibody (usually called the drug:antibody ratio-DAR), the targeting specificity, the biodistribution and its photophysical properties.

\subsection{Antibody Component of an ADP-Drug}

The limitations faced by the ADC researcher very often apply to the ADP field but the opposite is rarely true. Some of the main limitations of antibodies as therapeutics are [2,76]. (i) immunogenicityHumanization or fully human scaffolds tackle this problem but there remains a small issue with some non-germ-line sequences and small molecule/hapten-carrier effects; (ii) loss of specificity-Overcome by discovering antibodies with higher affinities and/or against better epitopes on well investigated targets or those unaffected by amino acid modifications; (iii) delivery kinetics-Using smaller, midaffinity fragments can facilitates delivery deeper into the tumour mass, (iv) half-life-Fragmentation may be used to shorten half-life, or modifications such as glycosylation or PEGylation to extend it, depending on application.

Despite limitations, antibodies offer clear advantages as carriers of PS-drugs, however the choice of antibody, as with ADC, can be complicated [2,77]. The target and affinity to which the antibody is raised will affect its efficiency, along with the level of humanization, selection of a suitable isotype [78], inclusion of the Fe domain [79,80], and production considerations in manipulation of post translational modification such as the inclusion of glycans [81]. Stability of antibody fragments [82,83], domain order [84,85], engineered increased valency [86] and the inclusion and length of any stabilizing linker [87] may also be important.

For ADP, antibody size needs careful consideration: Whole immunoglobulins have a long serum half-life and so can achieve a higher absolute level in the tumour, this is alongside higher non-specific uptake and an increased ability to elicit immune responses via the Fc domain $[80,88,89]$. With respect to ADP, prolonged residence could result in protracted skin and eye photosensitivity that significantly hampered conventional PDT. Furthermore, solid tumours can be difficult to saturate with larger biomolecules due to physiological limitations such as poor vascularisation, drainage, interstitial pressure and dense stroma [43]. This may be overcome by using faster clearing, smaller mid-affinity antibody fragments [89-91]. In fact, the slow elimination of some PS-drugs introduces the need for bio-conjugation to speed up small molecule clearance, rather than extend it as is the normal situation with chemo-active drugs.

Another consideration is antibody specificity. Heterogeneous expression of tumour targets raises issues of non-targeted killing and escape variants. This is particularly pertinent to the field of ADCs as researchers are actively dissecting drug killing mechanisms and learning that some drugs are better at 
diffusing into non-antibody bound cells, or activating cell mechanisms or signalling to exhibit a by-stander killing effect. The promiscuous nature of cellular organelle damage is an advantage in PDT but the short half-life of the ROS can limit the extent of PDT effect. However, PDT does show induction of by-stander effect $[92,93]$. Manipulation of the cell death mechanisms and downstream systemic events after PDT also adds potential for addressing this. Conversely, PDT can also be made so specific via choice of PS, activation regime and antibody targeting as to directly occlude a single blood vessel [94] or destroy specific intracellular structures [95,96] while sparing surrounding structures.

\subsection{Drug and Linker Components of an ADP-Drug}

Conjugation techniques of PS-drug to antibody are closely linked to existing ADC literature, techniques and methods. Usually, it exploits reactive amino acids such as thiols (reduced cysteines) or amines (lysine side chains and $\mathrm{N}$-terminal amino acids) that are accessible to solvent, and a designed activating group on the "drug". These are reacted together under the right conditions for both effective chemistry and protein stability. Many possible conjugation chemistries exist [97]. The current conjugation techniques between PS-drug and antibody that have been used include direct conjugations via carbodiimide coupling, activated esters, reductive amination, conjugations via isothiocyanate, maleimide or acryloyl moietys, and indirect conjugation of PS-drug onto polymeric linkers such as dextran, polylysine, PVA, polyglutamic acid, fullerene or HPMA before subsequent conjugation of this loaded carrier to the antibody. The use of different conjugation techniques in ADP production has been discussed recently [98,99], some of which are summarised in Table 3. Investigation into different conjugation chemistries has already been shown to, and will further help prevent, common problems encountered with PS conjugation. Many of the important factors to consider in the choice of PS for ADP-drugs are the same as for non-targeted PDT.

Table 3. Some common chemical linkages for antibody targeted PDT. Common types of chemical linkages that have been used to covalently attach PS-drugs to antibodies or antibody fragments [97].

\begin{tabular}{|c|c|c|c|}
\hline $\begin{array}{l}\text { Reactive } \\
\text { chemical } \\
\text { group on } \\
\text { antibody }\end{array}$ & Reactive chemical group / linking group on PS & Type of bond formed & Reference \\
\hline $\begin{array}{l}\mathrm{NH}_{2} \\
\text { (Amine) }\end{array}$ & $\begin{array}{l}\text { COO- (Carboxylate) } \\
\text { Activated via a carbodiimide to an } \mathrm{O}_{\text {-acylisourea }} \\
\mathrm{NB} \text { : Effciency can be increased by reaction via an } \\
\mathrm{NHS} \text { intermediate (see below) }\end{array}$ & Amide bond & {$[100-104]$} \\
\hline
\end{tabular}


Table 3. Cont.

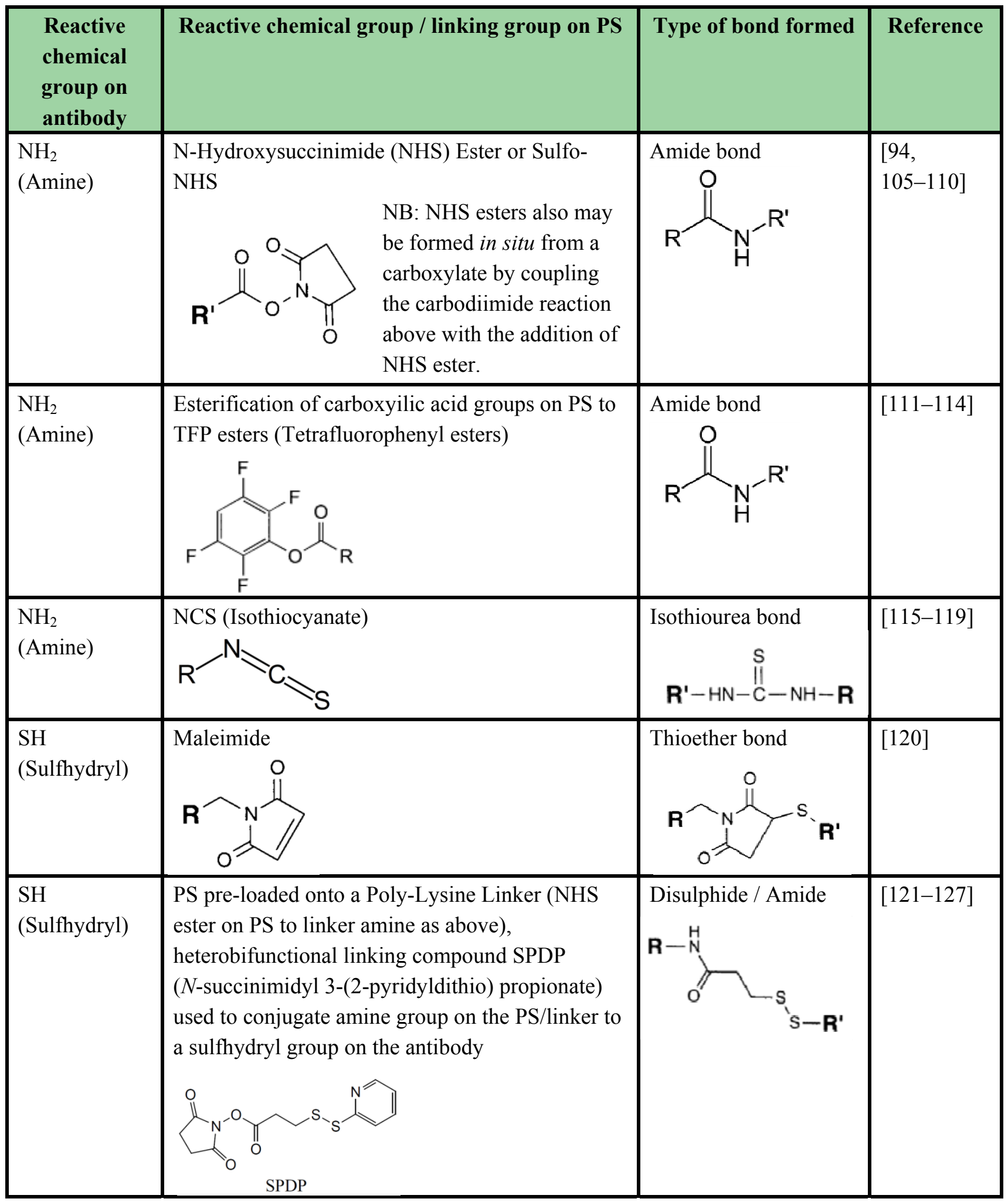


Table 3. Cont.

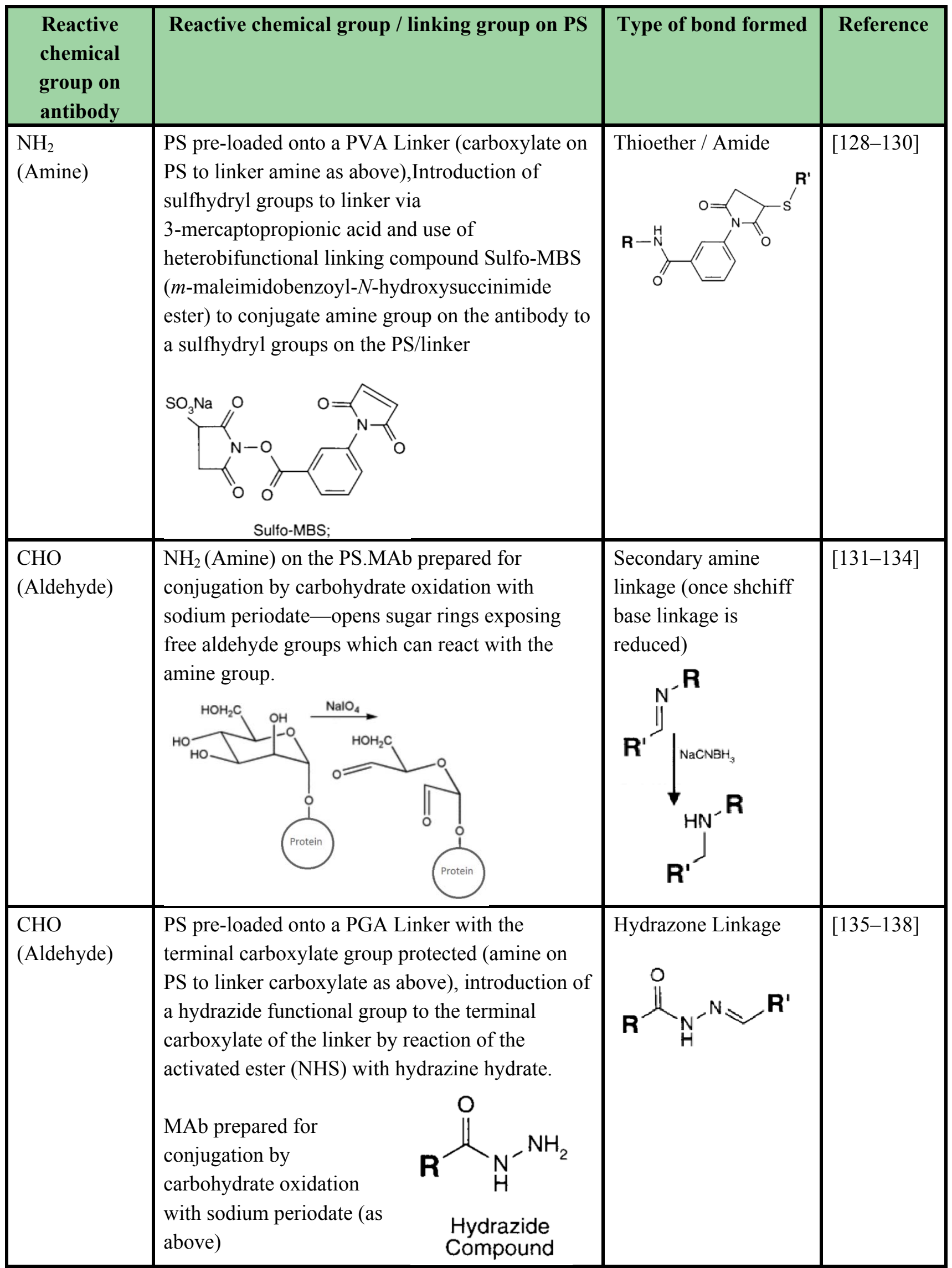


It is often the PS-drug rather than the antibody that is specifically modified for its use in bioconjugations, though this does not always have to be the case. The PS is usually modified with a single reactive group for conjugations. Occasionally additional solubilising moieties such as PEG chains and positive/negative charges facilitate bioconjugation in aqueous solutions and/or retention of antibody pharmacokinetic properties after loading. It was previously argued that for ADP-drugs the higher the DAR, the more efficient and potent the ADP-drug would be. Emerging data now suggests the optimal DAR is a characteristic of the specific conjugate, and ADP-drug needs to be optimised for the given antibody to maximise tolerated loading for the antibody whilst not affecting its tumour binding (see Section 3.4). A key difference between ADCs and ADP-drugs is that ADP-drugs do not require any release mechanism. The PS-drug remains photo-active when attached to peptides and is 'catalytic' in that it will generate the cytotoxin (ROS) continually when illuminated. Thus the general emphasis in ADP drug/linker design is to make this linker stable to avoid any non-specific toxicity. The pharmacokinetics of the free PS-drug varies significantly; highly charged/hydrophilic PS-drugs can clear within hours much like small molecules whereas more hydrophobic PS-drugs can adhere to serum proteins to display prolonged half-lives (weeks) $[44,56]$.

The current state of the ADP field has shown that antibody photosensitiser conjugates can exhibit an increased rate of cellular uptake and prolonged cellular retention compared to free PS. They further have the ability to be more selective and more effective at cancer destruction than free PS both in vitro and in vivo, and have been shown to produce complete cures in a number of different mouse models of cancer $[107,110,139]$. More detail of the scientific work carried out on ADPs is discussed in Section 4).

\subsection{Issues in Making ADP-Drugs}

Photosensitiser-drugs tend to be hydrophobic/poorly water soluble drugs and some issues that arise during ADP-drug bioconjugation reactions are: (1) The ability to reproduce an ADP-drug sample of the same consistency every time; (2) The removal of non-covalently associated PS; (3) Maintaining the efficiency and specificity with which the resulting ADP-drug targets and binds its antigen along with maintained pharmacokinetic profiles; (4) Retained ADP-drug photo-physical efficiency and hence potency in vitro and in vivo.

Following the conjugation maintaining both the biological activity of the antibody and the photo-physical properties of the PS-drug is paramount. It is important that the resulting conjugate is stable and soluble and the PS-drug does not leech out into the system leading to non-specific toxicity. Many of the drugs in the ADC field, for example auristatin and maytansine-based microtubule binders, are extremely potent and so unsuitable for non-targeted therapy [140]. For these drugs low DARs are sufficient for potency. Some second generation PS show pM potency as free drugs at high light doses, however it is generally accepted that higher loading is preferable after taking into account the physico-chemical effects this can have on the overall ADP-drug. In ADP, PS over-loading can lead to photophysical quenching between both neighbouring PS and the antibody and PS [105,137,141,142], too much of this quenching will reduce potency. It is also noted that excessive or non-optimised DARs can lead to conjugate aggregation and precipitation [104,112,114,116], losses in antibody immune-reactivity [104,106,116,117] or altered pharmacokinetic profiles [112-114,121,122]. An efficient PS-drug is normally monomeric in its solution in order to avoid self-quenching by aggregation, various methods that allow spatial separation of the bound molecules can help address 
this once PS has been conjugated $[120,139,143,144]$. PS-drug design is important in ensuring that the resulting conjugate retains its water solubility. The use of detergents can also resolve aggregation issues however this is not favoured due to the difficultly of removing unwanted surfactants from final ADP-drug products.

The crude ADP product after conjugation usually requires purification from the excess un-reacted PS-drug. This can be challenging as PS-drugs are notorious for non-specifically binding to proteins via hydrophobic interactions and this is one of the challenges in ADP-drug production. The presence of non-covalently attached PS-drug has two main limitations: (1) It leads to systemic, non-specific toxicity if the PS-drug leeches out into the system; (2) It makes the characterisation and quality assurance of the ADP-drug more difficult — hindering its development as a drug.

Obtaining maximum antibody loading with the minimal amount of unreacted non-covalently associated PS-drug can be driven via intelligent PS-drug design and reaction optimisation.

A genetically encoded photosensitser based on a homologue of green fluorescent protein (anm2CP0) has been developed [145,146]. Via manipulation of the chromophore properties using mutagenesis, a photoactive variant was produced that could generate reactive oxygen species. It was called "killer red" and is particularly influential in terms of bioconjugation as classical chemical reactions requiring harsh conditions and subsequent purification is completely negated if the PS can be encoded and expressed as a fusion protein. Work by Deyev et al. [147,148] produced such photo-immunoconjugates and showed specific photo activity and cell killing in vitro, although at the moment not as potently as traditional chemical conjugates.

\section{ADP-Drug Development}

\subsection{First ADP-Drugs}

Photo-immunotherapy was first described by Levy et al. in 1983 [101]. This first ADP-drug involved the formation of amide bonds between the acid group of the photosensitiser (HPD) and amine groups on the antibody by hydrolysation of the acid via a carbodiimide moiety. The antibody in question was an Anti M-1 (a rhabdo-myosarcoma antigen) monoclonal antibody. Even at this early stage the problem with non-covalently bound PS and subsequent ADP-drug purification was apparent. With this ADP-drug they were able to demonstrate both superior specificity and efficiency in antigen positive over antigen negative tumour cell lines, both in vitro and in vivo in mouse tumour models, when they compared the ADP-drug to equivalent concentrations of free photosensitiser or antibody. Two years later [100], different conjugates were described, and technological advances allowed them to use a more powerful laser to activate the ADP-drug compared to the fluorescent light previously used. Levy et al. then followed up this work using ADP-drugs to eliminate a select population of tumour reactive $\mathrm{T}$-suppressor cells in mice, allowing them to then elicit an immune response and reject re-planted syngeneic tumours [102]. Others have followed targeting T-cells in haematological cancers, e.g., leukaemia [149] but most research has focussed on solid tumours. 


\subsection{ADP-Drug Development for Cancer with Whole Immunoglobulins}

In between the first steps and today, significant scientific developments have helped shaped the field of ADP-drugs: The increase in new synthetic and/or chemically modified PS-drugs (with a range of photophysical and pharmacokinetic properties) has improved alongside a growth in the understanding of the important aspects for effective PDT. The field of antibody engineering has also expanded exceptionally including the discovery and recombinant protein production of antibodies and their fragments, now practically routine and well-established.

Initial problems of poor PS reproducibility led to a switch of PS-drug from the highly variable first generation natural products, like HPD, to new PS-drugs developed via chemical synthesis techniques. These early PS sometimes suffered from the presence of multiple chemically-active groups increasing the risk of cross-linking and making specific conjugation troublesome. Early PS were also prone to losses in photo physical efficiency upon conjugation, one of the earlier strategies used to overcome this was to increase drug loading via indirect coupling (first described by Hasan, a pioneer in the area of targeted PDT and photo-imaging). This strategy is distinct to the use of polymers to enhance overall ADP-drug solubility or stability. Indirect coupling is the use of a carrier or scaffold to initially load the PS-drug; this is then attached to the antibody. Indirect coupling allows the use of a wider range of chemistries for attachment (not restricted to amino acids side chains) and purification of the pre-loaded fragment. It can also be used to carry out site-specific conjugation to sites directed away from the regions important for antibody-binding, thus better preserving immunoreactivity. However, if functional groups are too closely-packed on such carriers, it can still lead to photo-physical quenching.

Hasan et al. [135-138] originally used a poly-glutamic acid (PGA) linker pre-loaded with the PS-drug chlorin e6, attached onto the carbohydrate moieties of an IgG away from its antigen binding region. Loading ratios were high with around 20 PS per linker and 1-2 linkers per IgG, however these conjugates showed evidence of cross linking and the formation of a mixture of products along with significant levels of non-covalently bound PS-drug. Additionally some loss of antibody binding was seen when compared to IgG alone. Despite this they did show some specificity and improved toxicity over free PS-drug in vitro and in vivo. Higher dosage levels induced fatal side effects, which were partially resolved by fractionated light delivery. Later work from this group [121,125,127] utilised a different pre-loaded poly-L-lysine linker which could be modified to bear a positive or negative charge. This charge was shown to affect ADP-drug intracellular localisation (cationic was vesicular and anionic was diffuse), in vitro cellular uptake (greater uptake with cationic) and in vivo tissue distribution (faster blood clearance with cationic, greater overall tumour uptake with anionic). They conjugated the PS-drug chlorin e6 via this poly-L-Lysine linker onto a full IgG molecule targeting EpCAM; an internalising antigen. Conjugation was to a lower extent, only 4-5 PS-drugs per lysine linker molecule and 1 or 2 linker molecules per IgG. Unfortunately this work also showed evidence of a loss in native antigen binding and non-antigen dependent uptake of the ADP-drugs alongside significant toxicity, even with a corresponding ADP-drug against an irrelevant antigen.

A different approach was shown by Levy et al. [128-130] in which they preloaded Polyvinyl alcohol (PVA) carrier molecules with the PS-drug benzoporphyrin derivative monoacids ring A (BPD-MA), also called Verteporfin, (the active drug in the approved product, Visudyne ${ }^{\mathrm{TM}}$ ). This was then conjugated onto solvent accessible antibody surface lysine residues. Using this technique they 
could load up to 25 PS-drug molecules per carrier and 1 carrier per IgG. Unfortunately they also showed non-covalently bound PS-drug and the conjugation of multiple carriers would cause extensive cross linking of the Ab. In vitro testing of these drugs also showed killing of irrelevant cells not expressing the target receptors.

Hasan's earlier refinement of specific conjugation via the carbohydrate was followed by many researchers (this and early targeted PDT research is reviewed in [150]). Importantly, this early work also showed for the first time that antibody internalisation is not necessary for efficient ADP. A few studies have attempted to directly compare ADP with internalising and non-internalising antibodies; and although not a requirement for potency it seems internalising ADP-drugs may have an advantage. For example: ADP-drug production carried out under Pelegrin and co-workers [103] conjugated the relatively hydrophilic tetrasulfonated aluminum phthalocyanine (AIPcS4) PS via an amide bond to IgG antibodies against either CEA (non internalising) or HER 2 (internalising) antigens. They engineered a cell line to express equimolar amounts of each antigen on the surface and showed that, with similar PS-drug conjugates of between 6-9 PS-drug per IgG, the internalising ADP-drug was around 50-times more potent in vitro.

Highly loaded ADP-drugs posed many technical problems, so more effective PS or ADP conjugation techniques were being developed, meaning an avoidance of PS-drug self-quenching and higher retention of antibody binding and solubility. Hasan et al. [108], via a very popular method, coupled around 5 chlorin e6 PS-drugs directly to an anti-EGFR MAb (cetuximab-Erbitux ${ }^{\mathrm{TM}}$ ); this was done via $N$-hydroxysuccinimidyl activated ester groups (NHS esters) on the PS-drug which react with various solvent exposed protein surface nucleophiles, most preferentially the $\varepsilon$-amine on lysine residues [97], to form stable amide bonds. In this study, they also created a diagnostic conjugate using cetuximab conjugated (in the same way) but to a near-infrared fluorescent dye. This was used for diagnostic fluorescent imaging before and after PDT treatment. No analyses on the quality of the ADP-drug was presented, however, PDT treatment led to an observable reduction in fluorescence signals with the diagnostic conjugate in the hamster cheek oral cancer model, backed up with histological studies that suggested successful eradication of EGFR-positive cells [108].

Work with a model hydrophilic dye by Pelegrin et al also showed the potential that effective, highly loaded, directly conjugated ADP-drugs can indeed be obtained [141]. Fluorescein molecules were conjugated to an anti CEA IgG, conjugation ratios were then tested of between 0 and 19 dyes per $\operatorname{IgG}$ and they showed when the DAR (dye to antibody ratio) was below 10 affected neither tumour localisation or tissue bio-distribution. When the DAR was above 10 both half-life and tumour localisation fell dramatically. When the same antibody was directly conjugated to the relatively hydrophilic PS-drug $\mathrm{AIPcS}_{4}$ via the same technique [104], they produced ADP-drugs with DARs of 5, 12 and 16 and showed that when compared to the free $\operatorname{IgG}$ all conjugates retained their tumour retention and specificity in vivo. However when studied in vitro, they showed no enhanced cytotoxicity over a similar conjugate with an irrelevant antigen; possibly due to non-covalently bound PS-drug or an aggregation of ADP-drugs.

Another important concept in ADP-drug production was the idea that newer, more hydrophilic PS-drugs, (not normally as toxic as previously developed PS-drugs when used as free agents and which cannot easily pass into cells), would become much more effective when delivered through a receptor via an antibody or ligand. This was shown by initial work by Van Dongen's group [111-114] 
in which they produced direct amide linkage conjugations between various internalising and non-internalising IgG antibodies and various PS-drug of different solubility, including the hydrophobic PS-drug m-tetrahydroxyphenylchlorin (mTHPC) $\left(\right.$ Foscan $^{\mathrm{TM}}$ ) and the relatively hydrophilic PS AIPcS . For all the ADP-drugs they found conjugation efficiencies above 2-3 molecules of PS-drug per Ab was limited by aggregation of the IgG and a subsequent loss during purification. When tested in vitro the results indicated that the more hydrophobic PS-drug showed lower or equal uptake and toxicity when conjugated compared to its comparable free PS-drug, and the more hydrophilic PS-drug showed equal or higher uptake and toxicity when conjugated than their comparable free PS-drug. The internalising $\mathrm{AIPcS}_{4}-\mathrm{ADP}$-drug was 7500 -fold (an impressive $\mathrm{IC}_{50}$ of $120 \mathrm{pM}$ ) more potent than the free PS-drug when internalised and interestingly this was also 60-times more potent than the equivalent mTHPC-based ADP-drug. Potency was also high with the non-internalising AIPcS4ADP-drug $\left(\mathrm{IC}_{50}\right.$ around $\left.5 \mathrm{nM}\right)$. Disappointingly, these in vitro results did not translate into in vivo efficacy, which did show selective tumour localisation of the ADP-drugs but for nearly all the conjugate combinations a higher coupling ratio would clear faster and/or was taken up into the tumour less. Liver accumulation of PS-drug was also seen to increase, especially with the hydrophobic PS-drug which suggests uptake of hydrophobic aggregates.

In a strategy to overcome the continual lack of purity and presence of aggregates in the existing highly-loaded ADP-drugs, work between the Savellano and Hasan labs [105,151] conjugated Verteporfin to an anti-EGFR MAb (cetuximab) using polyethylene glycol chains on the antibody to enhance overall solubility of the conjugate. The PEG chains were first covalently attached onto around 3 of the antibody's lysine residues and then the NHS-ester of the PS-drug was coupled to a number of the remaining free lysines in the antibody. A high concentration of organic solvents was used during conjugation and purification, (50\% DMSO), shown to be the limit for this antibody but which could potentially damage other proteins. Loading ratios of 7-10 PS-drugs per antibody were obtained, anything more than 11 resulted in a loss in antibody binding and yields dropping during purification, less than 7 drugs saw significant loss in cytotoxicity. They achieved a credible $<5 \%$ non covalently bound PS-drug, and in vitro toxicity assays showed specificity for the target antigen and cell death that could be competed with free IgG; showing its reliance on antigen dependent uptake. However the light dose required for potency was much higher than that needed for free un-conjugated PS-drug and to obtain equivalent uptake levels to free PS-drug the ADP-drug had to be incubated for $40 \mathrm{~h}$ ( $v s .4 \mathrm{~h}$ for the free PS-drug). There was also significant loss of photophysical efficiency with the ADP-drug (almost 10-fold at the highest loading) when compared to predicted levels of free PS-drug.

Savellano et al. [106] used a similar technique but conjugated the particularly photo-efficient PS, Pyropheophorbide- $a$ (PPa) to two mouse IgG antibodies against different epitopes of HER2 via the NHS ester technique as mentioned before. The antibodies were both PEGylated with varying numbers of branched PEG-NHS (10KDa) then subsequently reacted with the PPa-NHS. Two batches were produced with estimated DARs of moderate (4-5) and high (8-10), although questions were raised over the reliability of these ratios as PS spectra were shifted upon conjugation. Non-covalently bound PS was analysed by SDS PAGE to show 2-3\% and 10-20\% for moderate and high level conjugates respectively. The potency with these conjugates was not as effective as with free PPa even when intracellular PS concentrations were equivalent. However ADPs were shown to be much more specific than free drug when tested in vitro in cell lines that did/did not express HER2. Recent work from this 
lab [139] has led to the development of a new PPa molecule chemically modified with a branched peptide moiety allowing for the attachment of a short linear PEG chain for higher water-solubility. They conjugated this via an NHS-ester method to two clinically established IgG antibodies cetuximab and trastuzumab. The ADP drugs produced showed good water solubility and stability over time, the total DAR was around 11-14 PS per antibody but the non covalent portion of this PS-drug was shown to be particularly high, in some cases up to $42 \%$. Despite this they showed surprising specificity in vitro, the assumption made that the non-covalent portion was not easily leached. In vivo models of tumour bearing mice nevertheless showed no complete cures in a variety of regimes when compared to the free PS.

Conjugations of antibodies with other novel third-generation PS-drugs include Boyle et al. [116,118,119] who conjugated various $\mathrm{IgG}$ antibodies, both internalising and non internalising, directly to two isothiocyanate activated porphyrins (one with 3 dihydroxy phenyl groups, the other with 3 positively charged methyl pyridimium groups). Like an NHS ester, isothiocyanate also reacts with protein nucleophiles such as $\varepsilon$-amine on lysine but creates a stable isothiourea linkage instead of an amide bond. They showed the inclusion of cationic charges on the PS aided solubility and a reduction in non-covalently bound PS-drug in the ADP-drug. Final conjugates of these cationic PS-drug were pure, and showed no loss of antigen binding alongside some promising in vitro cell kill results despite conjugation ratios only being 1.5-2.5 PS-drug per IgG. In vivo however an increase in conjugation ratio caused a correlated decrease in tumour uptake, thought to be due to increased blood clearance. They too also saw some non specific toxicity.

\subsection{ADP-Drug Development for Cancer Using Antibody Fragments}

The ability of smaller antibody derivatives to clear more rapidly and penetrate tumours more effectively has been recognised (see earlier), and ADP-drugs using antibody fragments have been studied more or less in parallel with whole antibody ADP-drugs. The first fragment ADP-drug was described by the Hasan group in 1996 [122-124,126]. Here, the same indirect poly-L-Lysine linker technology was used (see above), but with a a $\mathrm{F}(\mathrm{ab})_{2}$ fragment of the same antibody (OC125). Conjugation ratios achieved were around 15-20 PS-drug per $\mathrm{F}\left(\mathrm{ab}^{\prime}\right)_{2}$ with the cationic or anionic linker. In vitro the cationic $\mathrm{F}\left(\mathrm{ab}^{\prime}\right)_{2}$ conjugates showed good specificity, higher uptake and better potency than all other ADP-drugs and controls, even when compared to the original cationic conjugate of the full $\mathrm{IgG}$ molecule. Binding to cells expressing antigen was also maintained relative to unmodified $\mathrm{Ab}$. In vivo however, although they showed some improvement in survival times when ADP-drug was injected intra-peritoneally, these ADP-drug variations still exhibited high non-specific tissue toxicity, and showed a marked separation of antibody and PS-drug post injection. Perhaps indicative of the presence of non-covalently bound PS.

Even smaller fragments were studied alongside full IgG ADP-drugs. Boyle's group (see above) synthesised their isothiocyanate activated porphyrins (with either 3 dihydroxy phenyl groups or 3 positively charged methyl pyridimium groups) and conjugated them to the single-chain variable fragment (scFv) [117] of the same full $\mathrm{IgG}$ they had used in previous work. A scFv molecule comprises the variable regions of the heavy and light chains of an antibody connected with a short linker peptide. For the hydroxyl PS-drug; 4-20 PS-drug were coupled to the scFv but all final ADP-drugs lost their binding affinity to antigen. High-loading is understandably more of an issue with 
scFvs when you consider their small size $(\sim 30 \mathrm{kDa})$. For the pyridinium PS-drug ratios were reduced to $0.67-1.2$, and these retained effective binding efficiency. However despite some success in in vitro cell kills the problem of significant non-specific toxicity that was seen with the full IgG was also seen with these scFv conjugates.

In other early ADP studies under Neri et al., the human antibody fragment scFv, L19 was used. L19 binds with an impressive picomolar affinity to the EDB domain of fibronectin (a well-characterised target for tumour neovasculature [152,153]), and was conjugated to bis(triethanolamine) $\mathrm{Sn}(\mathrm{IV})$ chlorin e6 $\left(\mathrm{SnCe}_{6}\right)$. The resulting ADP-drug was efficient at causing occlusion to the newly formed blood vessels of a rabbit eye model by promoting apoptosis. Importantly they also observed that healthy vasculature was unharmed, demonstrating the potential of targeted PDT to spare healthy tissue [94]. The use of an anti-angiogenic antibody also has applications in tumour targeting, and in later work the L19 was reformatted to a bivalent 'small immunoprotein' (SIP) molecule, (two scFvs dimerised by an IgE CH4 domain), and conjugated to the PS-drug $\mathrm{SnCe}_{6}$ [109]. When targeting tumour vasculature, vessel damage can induce thrombosis causing the tumour to become hypoxic and starved of nutrients, subsequent tumour infarction can be observed, followed by tumour mass regression. However in in vivo experiments with these ADP-drugs, despite significant tumour growth delay and even cures in a number of the mice, when mice were allowed to live past the treatments end, the cancer was seen to grow back. Importantly though, as seen from this work, despite being an noninternalising ADP-drug, it appears to still be very potent.

Using two different conjugation strategies, the more aqueously-soluble cationic porphyrins from the Boyle group were then conjugated to this extremely effective L19-SIP antibody from the Neri group. The conjugates were made in two different ways but both showed promising results when tested in vitro or in vivo. Boyle et al. [120] presents a site specific conjugation of the PS-drug, in this case derived with a maleimide group, to two $\mathrm{C}$-terminal cysteines residues, one genetically engineered onto the end of each SIP monomer. Tertiary folding of the antibody means these two groups were close together in space in the final molecule so an awareness of any possible PS-drug quenching was important. As a tool to investigate this they changed the length of linker between the porphyrin and maleimide. One PS-drug was linked directly, another had a short hydrocarbon spacer $\left(\mathrm{CH}_{2}\right)_{4}$, and another had a longer hydrocarbon spacer $\left(\mathrm{OCH}_{2} \mathrm{CH}_{2}\right)_{7}$. This longest linker was also designed like a PEG to increase hydrophilicity a bit further. Conjugation was shown to go to completion by mass spectrometry analysis i.e. one PS-drug per SIP monomer, they also showed conjugation did not affect SIP dimerisation or its ability to bind antigen. The conjugates were pure and showed no non-covalently bound PS-drug on SDS PAGE. Photo-toxicity in vitro showed the ADP-drug with the longest linker was significantly more toxic (factor of 10) then the mid length linker and this in turn was more toxic then the direct PS-drug, suggesting quenching of the PS-drug with smaller linkers. Specificity was maintained and there was lack of any killing in a cell line not expressing the antigen.

Neri et al. [110] also used the L-19 SIP and the 3 methyl pyridimum group PS-drug, but instead coupled non-site specifically via an NHS ester to the available lysine $\varepsilon$-amines on the antibody. These conjugates were shown by mass spec to present as a poisson distribution over a number of molecular masses with an average of 3 PS-drug per monomeric SIP (6 per dimer). The ADP-drug could still form dimers, had no free PS-drug, and binding to immobilised antigen on sepharose was over $90 \%$ retained. In vivo experiments showed the ADP-drug retained its highly selective tumour vascular targeting 
compared to the free $\mathrm{Ab}$. In therapy experiments, in which they added 10 fold less PS-drug (within ADP-drug) compared to the standard treatment dose for free PS-drug, the ADP-drugs showed a very strong anti-cancer response. Complete tumour eradication was shown alongside complete and prolonged cures in 4/4 mice treated. Comparatively, an irrelevant SIP-ADP-drug, un-irradiated ADP-drug or non-conjugated L19 showed no impairment in tumour growth. Upon closer inspection tumour histology showed disruption of tumour blood vessels, extensive haemorrhage, oedema and widespread cell death. Of additional interest is that when they carried this out in mice deficient in NK cells; only transient tumour growth arrest was seen, implying an immune element was important to the complete cures.

Our own work also centres around scFvs, combining the benefits of a faster pharmacokinetic profile with a more potent PS-drug, pyropheophorbide-a. Deonarain and co-workers also proposed that the genetic design of a PDT-favourable antibody framework was important for the idea of increased $\mathrm{scFv}$ loading while retaining PS photophysics [107]. When comparing ADP-drugs based on 5 different scFvs (with both verteporfrin and PPa), they observed that one particular anti-HER2 scFv (C6.5) formed consistently better ADP-drugs in terms of loading ratios and potency, they proposed that this antibody framework, by virtue of its high number and well-separated surface lysine residues, favoured ADP-drug synthesis and that these properties could be transplanted onto other antibody frameworks. Two of the anti-tumour ADP-drugs made (C6.5-PPa (anti-HER2) and MFE-23-PPa (anti-CEA)), were tested further in vitro and showed selective cyto-toxicity towards their respective antigen-expressing tumour cell lines. In vivo blood clearance of the scFv ADP-drugs was show to be optimal, i.e., quicker than whole IgG alone or PPa alone, but longer than the free $\mathrm{ScFv}$ alone. In therapy experiments the most potent ADP-drug (C6.5-PPa) was able to completely destroy SKOV3 human tumour xenografts in a nude mouse animal model after three PDT cycles. Further mechanistic work on these ADP drugs [142] confirmed that although the C6.5-PPa conjugate was efficiently internalised, and was likely to show enhanced cellular retention compared to free PPa, significant levels of non-covalently bound PS was seen. In more recent work, our group have looked at designing new derivatives of PPa with small solubilising PEG chains or positive charges based on the need for more efficient bioconjugation and less non covalent bound material to produce better characterised ADP-drugs [154].

\section{The Outlook for ADP}

To date there are currently no clinical studies using ADP-drugs. The closest thing was an photoactive anti-CEA chimeric mAb conjugated to fluorescein, which was tested on patients with colorectal cancer [155]. Even though the results were positive, fluorescein is not a suitable PS-drug and it was not pursued. This was over 20 years ago, and we may yet be years away from any clinical trial of an ADP-drug. This review highlights drug development complexities for ADPs that are similar to ADCs, but in addition the therapeutic outcome of a potent ADP depends on additional clinical delivery parameters including optimisation of light dose. Companies such as Genentech, and ImmunoGen, are investing resources into studying the trafficking and metabolism of ADCs and although internalisation is thought to be via receptor-mediated endocytosis, with internalising ADCs are likely to trafficked to the endosomes/lysosomes, it is not clear what happens next. This is especially relevant to covalently linked ADPs. Current thinking is that PS-drugs exert more potency in membrane compartments, but little is known about PS-drug redistribution after antibody delivery. 
Addressing these points is key to understanding the mechanism of targeted PDT in order to develop better ADP-drugs.

Some new and interesting variations of the classical PDT method that could cross over into ADP are briefly mentioned below: Two photon PDT uses sub-picosecond pulsed lasers to deliver two photons in quick succession, providing a way of accessing a high energy excited state by using low energy photons. The nature of the laser also means that two photon PDT can penetrate deeper into tissues as well as be incredibly spatially specific [156-158]. Other interesting variations include Sonodynamic therapy (SDT), this involves the use of ultrasound to activate what are called sonosenitisers. Interestingly it is often the same photosensitive molecules that are used in PDT [159-161]. Certain gold containing photosensitisers or nanoparticles can also be used to produce heat in response to light activation in order to damage tumour tissues via a different method to PDT [162-164]. The development of quantum dots or other nanomaterials that will work alone or as energy transfer molecule linked to photosensitisers, includes the development of systems that could use ionizing radiation for example X-rays or gamma rays which can penetrate much deeper in order to activate the photosensitiser [165-168]. Specifically modified PS could also be used as combined magnetic resonance imaging probes and PDT agents [169,170]. A PDT-type treatment but without the photosensitiser has been developed that can use light to directly excite molecular oxygen [171]. Work has also been carried out to develop activation of the PS without having to use an external laser [172], a targeted PS that was co-incubated in the dark with luminol, so once internalised, could induce its own intracellular chemiluminescence within the target cells. The development of a genetically encoded photosensitser, named killer red (see earlier) is also particularity notable.

This review has focused on the treatment of solid cancers, but like non-targeted PDT, there are many different applications and variations to which ADPs could be applied. For example; re-application of the vessel specific shutdown or immune regulation designs for cancer could be used in many other disease models outside of cancer. ADP drugs have already been developed for infectious disease [131,143], including against drug resistant bacteria like MRSA [173]. ADPs have also been designed for the targeted removal of one cell population from a mixture, i.e., in the ex vivo cleaning of bone marrow transplants [174] or in vivo manipulation of wound healing [132]. As well as these larger scale effects, ADP drugs are being manipulated to induce effects so specific that they can destroy specific intracellular structures $[95,96]$, useful as laboratory tools.

\section{Conclusions}

Antibody-directed phototherapy promises to deliver the benefits of conventional PDT combined with the specificity and potency of antibody therapy. The area is expanding but needs commitment at the commercial and clinical level to facilitate this. As with many antibody technologies, antibody engineering and synthetic chemistry are leading to improved drug products and this is starting to produce ADP-drugs which one day may make it through to advanced clinical development.

\section{Acknowledgements}

We thank PhotoBiotics Ltd, the National Institute for Health Research, European Union and the Technology Strategy Board for funding var. 


\section{References}

1. Deonarain, M.P. Recombinant antibodies for cancer therapy. Expert Opin. Biol. Ther. 2008, 8, 1123-1141.

2. Carter, P.J. Potent antibody therapeutics by design. Nat. Rev. Immunol. 2006, 6, 343-357.

3. Business Insights, L. The Cancer Market Outlook to 2016. Business Insights Ltd (Product Code: BI00042-009): London, UK, 2011.

4. Aggarwal, S. What's fueling the biotech engine-2008. Nat. Biotechnol. 2009, 27, 987-993.

5. Scott, A.M.; Wolchok, J.D.; Old, L.J. Antibody therapy of cancer. Nat. Rev. Cancer 2012, 12, $278-287$.

6. U.S. Food and Drug Administration Home Page. Available online: http://www.fda.gov/default.htm (accessed on 12 April 2013).

7. The Antibody Society Home Page. Available online: http://www.antibodysociety.org/ (accessed on 12 April 2013).

8. ClinicalTrials.gov Home Page. Available online: http://www.clinicaltrials.gov/ (accessed on 12 April 2013).

9. Nahta, R.; Yu, D.; Hung, M.-C.; Hortobagyi, G.N.; Esteva, F.J. Mechanisms of disease: understanding resistance to HER2-targeted therapy in human breast cancer. Nat. Clin. Pract. Oncol. 2006, 3, 269-280.

10. Alley, S.C.; Okeley, N.M.; Senter, P.D. Antibody-drug conjugates: Targeted drug delivery for cancer. Curr. Opin. Chem. Biol. 2010, 14, 529-537.

11. Hughes, B. Antibody-drug conjugates for cancer: Poised to deliver? Nat. Rev. Drug Discov. 2010, 9, 665-667.

12. Adair, J.R.; Howard, P.W.; Hartley, J.A.; Williams, D.G.; Chester, K.A. Antibody-drug conjugates-A perfect synergy. Expert Opin. Biol. Ther. 2012, 12, 1191-1206.

13. Brown, S.B.; Brown, E.A.; Walker, I. The present and future role of photodynamic therapy in cancer treatment. Lancet Oncol. 2004, 5, 497-508.

14. Dolmans, D.E.J.G.J.; Fukumura, D.; Jain, R.K. Photodynamic therapy for cancer. Nat. Rev. Cancer 2003, 3, 380-387.

15. Brown, S.B.; Mellish, K.J. Verteporfin: A milestone in opthalmology and photodynamic therapy. Expert Opin. Pharmacother. 2001, 2, 351-361.

16. Babilas, P.; Schreml, S.; Landthaler, M.; Szeimies, R.-M. Photodynamic therapy in dermatology: State-of-the-art. Photodermatol. Photoimmunol. Photomed. 2010, 26, 118-132.

17. Celli, J.P.; Spring, B.Q.; Rizvi, I.; Evans, C.L.; Samkoe, K.S.; Verma, S.; Pogue, B.W.; Hasan, T. Imaging and photodynamic therapy: mechanisms, monitoring, and optimization. Chem. Rev. 2010, 110, 2795-2838.

18. Bonnett, R. Chemical Aspects of Photodynamic Therapy; Gordon and Breach Science Publishers: Amsterdam, The Netherlands, 2000.

19. Agostinis, P.; Berg, K.; Cengel, K.A.; Foster, T.H.; Girotti, A.W.; Gollnick, S.O.; Hahn, S.M.; Hamblin, M.R.; Juzeniene, A.; Kessel, D.; et al. Photodynamic therapy of cancer: An update. CA Cancer J. Clin. 2011, 61, 250-281. 
20. Lou, P.-J.; Jones, L.; Hopper, C. Clinical outcomes of photodynamic therapy for head-and-neck cancer. Technol. Cancer Res. Treat. 2003, 2, 311-317.

21. Hopper, C.; Niziol, C.; Sidhu, M. The cost-effectiveness of Foscan mediated photodynamic therapy (Foscan-PDT) compared with extensive palliative surgery and palliative chemotherapy for patients with advanced head and neck cancer in the UK. Oral Oncol. 2004, 40, 372-382.

22. Nyst, H.J.; Tan, I.B.; Stewart, F.A.; Balm, A.J.M. Is photodynamic therapy a good alternative to surgery and radiotherapy in the treatment of head and neck cancer? Photodiagnosis Photodyn. Ther. 2009, 6, 3-11.

23. Allison, R.R.; Sibata, C.H. Oncologic photodynamic therapy photosensitizers: A clinical review. Photodiagnosis Photodyn. Ther. 2010, 7, 61-75.

24. Schweitzer, V.G.; Somers, M.L. PHOTOFRIN-mediated photodynamic therapy for treatment of early stage (Tis-T2N0M0) SqCCa of oral cavity and oropharynx. Lasers Surg. Med. 2010, 42, 1-8.

25. Fien, S.M.; Oseroff, A.R. Photodynamic therapy for non-melanoma skin cancer. J. Natl. Compr. Canc. Netw. 2007, 5, 531-540.

26. Kochneva, E.V.; Filonenko, E.V.; Vakulovskaya, E.G.; Scherbakova, E.G.; Seliverstov, O.V.; Markichev, N.A.; Reshetnickov, A.V. Photosensitizer Radachlorin(R): Skin cancer PDT phase II clinical trials. Photodiagnosis Photodyn. Ther. 2010, 7, 258-267.

27. Moore, C.M.; Pendse, D.; Emberton, M. Photodynamic therapy for prostate cancer-A review of current status and future promise. Nat. Clin. Pract. Urol. 2009, 6, 18-30.

28. Trachtenberg, J.; Weersink, R.A.; Davidson, S.R.H.; Haider, M.A.; Bogaards, A.; Gertner, M.R.; Evans, A.; Scherz, A.; Savard, J.; Chin, J.L.; et al. Vascular-targeted photodynamic therapy (padoporfin, WST09) for recurrent prostate cancer after failure of external beam radiotherapy: a study of escalating light doses. BJU Int. 2008, 102, 556-562.

29. Selbo, P.K.; Weyergang, A.; Bonsted, A.; Bown, S.G.; Berg, K. Photochemical internalization of therapeutic macromolecular agents: A novel strategy to kill multidrug-resistant cancer cells. J. Pharmacol. Exp. Ther. 2006, 319, 604-612.

30. Josefsen, L.B.; Boyle, R.W. Photodynamic therapy: Novel third-generation photosensitizers one step closer? Br. J. Pharmacol. 2008, 154, 1-3.

31. Maisch, T. Anti-microbial photodynamic therapy: Useful in the future? Lasers Med. Sci. 2007, $22,83-91$.

32. Wormald, R.; Evans, J.; Smeeth, L.; Henshaw, K. Photodynamic therapy for neovascular age-related macular degeneration. Cochrane Database Syst Rev 2007, CD002030.

33. Tandon, Y.K.; Yang, M.F.; Baron, E.D. Role of photodynamic therapy in psoriasis: A brief review. Photodermatol. Photoimmunol. Photomed. 2008, 24, 222-230.

34. van der Snoek, E.M.; Robinson, D.J.; van Hellemond, J.J.; Neumann, H.A. A review of photodynamic therapy in cutaneous leishmaniasis. J. Eur. Acad. Dermatol. Venereol. 2008, 22, 918-922.

35. Wilson, B.C.; Patterson, M.S. The physics, biophysics and technology of photodynamic therapy. Phys. Med. Biol. 2008, 53, R61-R109.

36. Choudhary, S.; Nouri, K.; Elsaie, M.L. Photodynamic therapy in dermatology: A review. Lasers Med. Sci. 2009, 24, 971-980. 
37. Dai, T.; Huang, Y.Y.; Hamblin, M.R. Photodynamic therapy for localized infections - State of the art. Photodiagnosis Photodyn. Ther. 2009, 6, 170-188.

38. Huang, Z.; Xu, H.; Meyers, A.D.; Musani, A.I.; Wang, L.; Tagg, R.; Barqawi, A.B.; Chen, Y.K. Photodynamic therapy for treatment of solid tumors-Potential and technical challenges. Technol. Cancer Res. Treat. 2008, 7, 309-320.

39. Allison, R.R.; Mota, H.C.; Bagnato, V.S.; Sibata, C.H. Bio-nanotechnology and photodynamic therapy-State of the art review. Photodiagnosis Photodyn. Ther. 2008, 5, 19-28.

40. Mang, T.S. Lasers and light sources for PDT: Past, present and future. Photodiagnosis Photodyn. Ther. 2004, 1, 43-48.

41. Firczuk, M.; Nowis, D.; Gołąb, J. PDT-induced inflammatory and host responses. Photochem. Photobiol. Sci. 2011, 10, 653-663.

42. Freitas, I.; Baronzio, G.F. Tumor hypoxia, reoxygenation and oxygenation strategies: Possible role in photodynamic therapy. J. Photochem. Photobiol. B Biol. 1991, 11, 3-30.

43. Ferrari, M. Frontiers in cancer nanomedicine: Directing mass transport through biological barriers. Trends Biotechnol. 2010, 28, 181-188.

44. Castano, A.P.; Demidova, T.N.; Hamblin, M.R. Mechanisms in photodynamic therapy: Part three-Photosensitizer pharmacokinetics, biodistribution, tumor localization and modes of tumor destruction. Photodiagnosis Photodyn. Ther. 2005, 2, 91-106.

45. Sternberg, E.D.; Dolphin, D.; Brückner, C. Porphyrin-based photosensitizers for use in photodynamic therapy. Tetrahedron 1998, 54, 4151-4202.

46. Konan, Y.N.; Gurny, R.; Allemann, E. State of the art in the delivery of photosensitizers for photodynamic therapy. J. Photochem. Photobiol. B 2002, 66, 89-106.

47. Sharman, W.M.; van Lier, J.E.; Allen, C.M. Targeted photodynamic therapy via receptor mediated delivery systems. Adv. Drug Deliv. Rev. 2004, 56, 53-76.

48. Bechet, D.; Couleaud, P.; Frochot, C.; Viriot, M.L.; Guillemin, F.; Barberi-Heyob, M. Nanoparticles as vehicles for delivery of photodynamic therapy agents. Trends Biotechnol. 2008, 26, 612-621.

49. Bugaj, A.M. Targeted photodynamic therapy-A promising strategy of tumor treatment. Photochem. Photobiol. Sci. 2011, 10, 1097-1109.

50. Macdonald, I.J.; Dougherty, T.J. Basic principles of photodynamic therapy. J. Porphyr. Phthalocyanines 2001, 05, 105-129.

51. Hamblin, M.R.; Mróz, P.; Mroz, P. Advances in Photodynamic Therapy: Basic, Translational and Clinical; Artech House: Norwood, MA, USA, 2008.

52. Winterbourn, C.C. Reconciling the chemistry and biology of reactive oxygen species. Nat. Chem. Biol. 2008, 4, 278-286.

53. Redmond, R.W.; Kochevar, I.E. Spatially resolved cellular responses to singlet oxygen. Photochem. Photobiol. 2006, 82, 1178-1186.

54. Robertson, C.A.; Evans, D.H.; Abrahamse, H. Photodynamic therapy (PDT): A short review on cellular mechanisms and cancer research applications for PDT. J. Photochem. Photobiol. B Biol. 2009, 96, 1-8.

55. Oleinick, N.L.; Morris, R.L.; Belichenko, I. The role of apoptosis in response to photodynamic therapy: What, where, why, and how. Photochem. Photobiol. Sci. 2002, 1, 1-21. 
56. Boyle, R.W.; Dolphin, D. Structure and biodistribution relationships of photodynamic sensitizers. Photochem. Photobiol. 1996, 64, 469-485.

57. Castano, A.P.; Demidova, T.N.; Hamblin, M.R. Mechanisms in photodynamic therapy: Part one-Photosensitizers, photochemistry and cellular localization. Photodiagnosis Photodyn. Ther. 2004, 1, 279-293.

58. Mojzisova, H.; Bonneau, S.; Brault, D. Structural and physico-chemical determinants of the interactions of macrocyclic photosensitizers with cells. Eur. Biophys. J. 2007, 36, 943-953.

59. Almeida, R.D.; Manadas, B.J.; Carvalho, A.P.; Duarte, C.B. Intracellular signaling mechanisms in photodynamic therapy. Biochim. Biophys. Acta 2004, 1704, 59-86.

60. Tsaytler, P.A.; C O'Flaherty, M.; Sakharov, D.V.; Krijgsveld, J.; Egmond, M.R. Immediate protein targets of photodynamic treatment in carcinoma cells. J. Proteome Res. 2008, 7, 3868-3878.

61. Baglo, Y.; Sousa, M.M.L.; Slupphaug, G.; Hagen, L.; Håvåg, S.; Helander, L.; Zub, K.A.; Krokan, H.E.; Gederaas, O.A. Photodynamic therapy with hexyl aminolevulinate induces carbonylation, posttranslational modifications and changed expression of proteins in cell survival and cell death pathways. Photochem. Photobiol. Sci. 2011, 10, 1137-1145.

62. Moor, A.C. Signaling pathways in cell death and survival after photodynamic therapy. J. Photochem. Photobiol. B Biol. 2000, 57, 1-13.

63. Castano, A.P.; Demidova, T.N.; Hamblin, M.R. Mechanisms in photodynamic therapy: Part two-Cellular signaling, cell metabolism and modes of cell death. Photodiagnosis Photodyn. Ther. 2005, 2, 1-23.

64. Buytaert, E.; Dewaele, M.; Agostinis, P. Molecular effectors of multiple cell death pathways initiated by photodynamic therapy. Biochim. Biophys. Acta 2007, 1776, 86-107.

65. Pazos, M.d.C.; Nader, H.B. Effect of photodynamic therapy on the extracellular matrix and associated components. Braz. J. Med. Biol. Res. 2007, 40, 1025-1035.

66. Castano, A.P.; Mroz, P.; Hamblin, M.R. Photodynamic therapy and anti-tumour immunity. Nat. Rev. Cancer 2006, 6, 535-545.

67. van Duijnhoven, F.H.; Aalbers, R.I.J.M.; Rovers, J.P.; Terpstra, O.T.; Kuppen, P.J.K. The immunological consequences of photodynamic treatment of cancer, a literature review. Immunobiology 2003, 207, 105-113.

68. Korbelik, M. Cancer vaccines generated by photodynamic therapy. Photochem. Photobiol. Sci. 2011, 10, 664-669.

69. Wilson, B.C.; Patterson, M.S.; Lilge, L. Implicit and explicit dosimetry in photodynamic therapy: A New paradigm. Lasers Med. Sci. 1997, 12, 182-199.

70. Caldwell, J.; Gardner, I.; Swales, N. An introduction to drug disposition: The basic principles of absorption, distribution, metabolism, and excretion. Toxicol. Pathol. 1995, 23, 102-114.

71. Ochsner, M. Photophysical and photobiological processes in the photodynamic therapy of tumours. J. Photochem. Photobiol. B 1997, 39, 1-18.

72. Henderson, B.W.; Gollnick, S.O.; Snyder, J.W.; Busch, T.M.; Kousis, P.C.; Cheney, R.T.; Morgan, J. Choice of oxygen-conserving treatment regimen determines the inflammatory response and outcome of photodynamic therapy of tumors. Cancer Res. 2004, 64, 2120-2126.

73. Bachor, R.; Hautmann, R.; Hasan, T. Comparison of two routes of photosensitizer administration for photodynamic therapy of bladder cancer. Urol. Res. 1994, 22, 21-23. 
74. Kwitniewski, M.; Juzeniene, A.; Glosnicka, R.; Moan, J. Immunotherapy: A way to improve the therapeutic outcome of photodynamic therapy? Photochem. Photobiol. Sci. 2008, 7, 1011-1017.

75. Bown, S.G.; Rogowska, A.Z.; Whitelaw, D.E.; Lees, W.R.; Lovat, L.B.; Ripley, P.; Jones, L.; Wyld, P.; Gillams, A.; Hatfield, A.W. Photodynamic therapy for cancer of the pancreas. Gut 2002, 50, 549-557.

76. Nelson, A.L.; Reichert, J.M. Development trends for therapeutic antibody fragments. Nat. Biotechnol. 2009, 27, 331-337.

77. Deyev, S.M.; Lebedenko, E.N. Multivalency: The hallmark of antibodies used for optimization of tumor targeting by design. Bioessays 2008, 30, 904-918.

78. Salfeld, J.G. Isotype selection in antibody engineering. Nat. Biotechnol. 2007, 25, 1369-1372.

79. Roopenian, D.C.; Akilesh, S. FcRn: The neonatal Fc receptor comes of age. Nat. Rev. Immunol. 2007, 7, 715-725.

80. Golay, J.; Introna, M. Mechanism of action of therapeutic monoclonal antibodies: Promises and pitfalls of in vitro and in vivo assays. Arch. Biochem. Biophys. 2012, 526, 146-153.

81. Arnold, J.N.; Wormald, M.R.; Sim, R.B.; Rudd, P.M.; Dwek, R.A. The impact of glycosylation on the biological function and structure of human immunoglobulins. Annu. Rev. Immunol. 2007, 25, 21-50.

82. Rothlisberger, D.; Honegger, A.; Pluckthun, A. Domain interactions in the Fab fragment: a comparative evaluation of the single-chain Fv and Fab format engineered with variable domains of different stability. J. Mol. Biol. 2005, 347, 773-789.

83. Quintero-Hernández, V.; Del Pozo-Yauner, L.; Pedraza-Escalona, M.; Juárez-González, V.R.; Alcántara-Recillas, I.; Possani, L.D.; Becerril, B. Evaluation of three different formats of a neutralizing single chain human antibody against toxin $\mathrm{Cn} 2$ : Neutralization capacity versus thermodynamic stability. Immunol. Lett. 2012, 143, 152-160.

84. Carmichael, J.A.; Power, B.E.; Garrett, T.P.J.; Yazaki, P.J.; Shively, J.E.; Raubischek, A.A.; Wu, A.M.; Hudson, P.J. The crystal structure of an anti-CEA scFv diabody assembled from T84.66 scFvs in $\mathrm{V}(\mathrm{L})-\mathrm{to}-\mathrm{V}(\mathrm{H})$ orientation: implications for diabody flexibility. J. Mol. Biol. 2003, 326, 341-351.

85. Kipriyanov, S.M.; Moldenhauer, G.; Braunagel, M.; Reusch, U.; Cochlovius, B.; Le Gall, F.; Kouprianova, O.A.; Von der Lieth, C.W.; Little, M. Effect of domain order on the activity of bacterially produced bispecific single-chain Fv antibodies. J. Mol. Biol. 2003, 330, 99-111.

86. Cuesta, A.M.; Sainz-Pastor, N.; Bonet, J.; Oliva, B.; Alvarez-Vallina, L. Multivalent antibodies: when design surpasses evolution. Trends Biotechnol. 2010, 28, 355-362.

87. Todorovska, A.; Roovers, R.C.; Dolezal, O.; Kortt, A.A.; Hoogenboom, H.R.; Hudson, P.J. Design and application of diabodies, triabodies and tetrabodies for cancer targeting. J. Immunol. Methods 2001, 248, 47-66.

88. Kenanova, V.; Wu, A.M. Tailoring antibodies for radionuclide delivery. Expert Opin. Drug Deliv. 2006, 3, 53-70.

89. Yuan, F.; Dellian, M.; Fukumura, D.; Leunig, M.; Berk, D.A.; Torchilin, V.P.; Jain, R.K. Vascular permeability in a human tumor xenograft: Molecular size dependence and cutoff size. Cancer Res. 1995, 55, 3752-3756. 
90. Batra, S.K.; Jain, M.; Wittel, U.A.; Chauhan, S.C.; Colcher, D. Pharmacokinetics and biodistribution of genetically engineered antibodies. Curr. Opin. Biotechnol. 2002, 13, 603-608.

91. Rudnick, S.I.; Adams, G.P. Affinity and avidity in antibody-based tumor targeting. Cancer Biother. Radiopharm. 2009, 24, 155-161.

92. Dahle, J.; Bagdonas, S.; Kaalhus, O.; Olsen, G.; Steen, H.B.; Moan, J. The bystander effect in photodynamic inactivation of cells. Biochim. Biophys. Acta 2000, 1475, 273-280.

93. Rubio, N.; Fleury, S.P.; Redmond, R.W. Spatial and temporal dynamics of in vitro photodynamic cell killing: Extracellular hydrogen peroxide mediates neighbouring cell death. Photochem. Photobiol. Sci. 2009, 8, 457-464.

94. Birchler, M.; Viti, F.; Zardi, L.; Spiess, B.; Neri, D. Selective targeting and photocoagulation of ocular angiogenesis mediated by a phage-derived human antibody fragment. Nat. Biotechnol. 1999, 17, 984-988.

95. Conlon, K.A.; Berrios, M. Light-induced proteolysis of myosin heavy chain by Rose Bengalconjugated antibody complexes. J. Photochem. Photobiol. B 2001, 65, 22-28.

96. Conlon, K.A.; Rosenquist, T.; Berrios, M. Site-directed photochemical disruption of the actin cytoskeleton by actin-binding Rose Bengal-conjugates. J. Photochem. Photobiol. B 2002, 68, 140-146.

97. Hermanson, G.T. Bioconjugate Techniques; Academic Press: London, UK, 2008.

98. Bullous, A.J.; Alonso, C.M.A.; Boyle, R.W. Photosensitiser-antibody conjugates for photodynamic therapy. Photochem. Photobiol. Sci. 2011, 10, 721-750.

99. Giuntini, F.; Alonso, C.M.A.; Boyle, R.W. Synthetic approaches for the conjugation of porphyrins and related macrocycles to peptides and proteins. Photochem. Photobiol. Sci. 2011, 10, 759-791.

100. Mew, D.; Lum, V.; Wat, C.K.; Towers, G.H.; Sun, C.H.; Walter, R.J.; Wright, W.; Berns, M.W.; Levy, J.G. Ability of specific monoclonal antibodies and conventional antisera conjugated to hematoporphyrin to label and kill selected cell lines subsequent to light activation. Cancer Res. 1985, 45, 4380-4386.

101. Mew, D.; Wat, C.K.; Towers, G.H.; Levy, J.G. Photoimmunotherapy: treatment of animal tumors with tumor-specific monoclonal antibody-hematoporphyrin conjugates. J. Immunol. 1983, 130, 1473-1477.

102. Steele, J.K.; Liu, D.; Stammers, A.T.; Whitney, S.; Levy, J.G. Suppressor deletion therapy: selective elimination of $\mathrm{T}$ suppressor cells in vivo using a hematoporphyrin conjugated monoclonal antibody permits animals to reject syngeneic tumor cells. Cancer Immunol. Immunother. 1988, 26, 125-131.

103. Carcenac, M.; Dorvillius, M.; Garambois, V.; Glaussel, F.; Larroque, C.; Langlois, R.; Hynes, N.E.; van Lier, J.E.; Pèlegrin, A. Internalisation enhances photo-induced cytotoxicity of monoclonal antibody-phthalocyanine conjugates. Br. J. Cancer 2001, 85, 1787-1793.

104. Carcenac, M.; Larroque, C.; Langlois, R.; van Lier, J.E.; Artus, J.C.; Pèlegrin, A. Preparation, phototoxicity and biodistribution studies of anti-carcinoembryonic antigen monoclonal antibodyphthalocyanine conjugates. Photochem. Photobiol. 1999, 70, 930-936. 
105. Savellano, M.D.; Hasan, T. Targeting cells that overexpress the epidermal growth factor receptor with polyethylene glycolated BPD verteporfin photosensitizer immunoconjugates. Photochem. Photobiol. 2003, 77, 431-439.

106. Savellano, M.D.; Pogue, B.W.; Hoopes, P.J.; Vitetta, E.S.; Paulsen, K.D. Multiepitope HER2 targeting enhances photoimmunotherapy of HER2-overexpressing cancer cells with pyropheophorbide-a immunoconjugates. Cancer Res. 2005, 65, 6371-6379.

107. Bhatti, M.; Yahioglu, G.; Milgrom, L.R.; Garcia-Maya, M.; Chester, K.A.; Deonarain, M.P. Targeted photodynamic therapy with multiply-loaded recombinant antibody fragments. Int. J. Cancer 2008, 122, 1155-1163.

108. Soukos, N.S.; Hamblin, M.R.; Keel, S.; Fabian, R.L.; Deutsch, T.F.; Hasan, T. Epidermal growth factor receptor-targeted immunophotodiagnosis and photoimmunotherapy of oral precancer in vivo. Cancer Res. 2001, 61, 4490-4496.

109. Fabbrini, M.; Trachsel, E.; Soldani, P.; Bindi, S.; Alessi, P.; Bracci, L.; Kosmehl, H.; Zardi, L.; Neri, D.; Neri, P. Selective occlusion of tumor blood vessels by targeted delivery of an antibodyphotosensitizer conjugate. Int. J. Cancer 2006, 118, 1805-1813.

110. Palumbo, A.; Hauler, F.; Dziunycz, P.; Schwager, K.; Soltermann, A.; Pretto, F.; Alonso, C.; Hofbauer, G.F.; Boyle, R.W.; Neri, D. A chemically modified antibody mediates complete eradication of tumours by selective disruption of tumour blood vessels. Br. J. Cancer 2011, 104, 1106-1115.

111. Vrouenraets, M.B.; Visser, G.W.M.; Stigter, M.; Oppelaar, H.; Snow, G.B.; van Dongen, G.A.M.S. Comparison of aluminium (III) phthalocyanine tetrasulfonate- and metatetrahydroxyphenylchlorin-monoclonal antibody conjugates for their efficacy in photodynamic therapy in vitro. Int. J. Cancer 2002, 98, 793-798.

112. Vrouenraets, M.B.; Visser, G.W.; Stewart, F.A.; Stigter, M.; Oppelaar, H.; Postmus, P.E.; Snow, G.B.; van Dongen, G.A. Development of meta-tetrahydroxyphenylchlorin-monoclonal antibody conjugates for photoimmunotherapy. Cancer Res. 1999, 59, 1505-1513.

113. Vrouenraets, M.B.; Visser, G.W.; Loup, C.; Meunier, B.; Stigter, M.; Oppelaar, H.; Stewart, F.A.; Snow, G.B.; van Dongen, G.A. Targeting of a hydrophilic photosensitizer by use of internalizing monoclonal antibodies: A new possibility for use in photodynamic therapy. Int. J. Cancer 2000, 88, 108-114.

114. Vrouenraets, M.B.; Visser, G.W.; Stigter, M.; Oppelaar, H.; Snow, G.B.; van Dongen, G.A. Targeting of aluminum (III) phthalocyanine tetrasulfonate by use of internalizing monoclonal antibodies: improved efficacy in photodynamic therapy. Cancer Res. 2001, 61, 1970-1975.

115. Sutton, J.M.; Clarke, O.J.; Fernandez, N.; Boyle, R.W. Porphyrin, chlorin, and bacteriochlorin isothiocyanates: Useful reagents for the synthesis of photoactive bioconjugates. Bioconjug. Chem. 2002, 13, 249-263.

116. Hudson, R.; Carcenac, M.; Smith, K.; Madden, L.; Clarke, O.J.; Pèlegrin, A.; Greenman, J.; Boyle, R.W. The development and characterisation of porphyrin isothiocyanate-monoclonal antibody conjugates for photoimmunotherapy. Br. J. Cancer 2005, 92, 1442-1449.

117. Staneloudi, C.; Smith, K.A.; Hudson, R.; Malatesti, N.; Savoie, H.; Boyle, R.W.; Greenman, J. Development and characterization of novel photosensitizer: scFv conjugates for use in photodynamic therapy of cancer. Immunology 2007, 120, 512-517. 
118. Smith, K.; Malatesti, N.; Cauchon, N.; Hunting, D.; Lecomte, R.; van Lier, J.E.; Greenman, J.; Boyle, R.W. Mono- and tri-cationic porphyrin-monoclonal antibody conjugates: Photodynamic activity and mechanism of action. Immunology 2011, 132, 256-265.

119. Malatesti, N.; Smith, K.; Savoie, H.; Greenman, J.; Boyle, R.W. Synthesis and in vitro investigation of cationic 5,15-diphenyl porphyrin-monoclonal antibody conjugates as targeted photodynamic sensitisers. Int. J. Oncol. 2006, 28, 1561-1569.

120. Alonso, C.M.A.; Palumbo, A.; Bullous, A.J.; Pretto, F.; Neri, D.; Boyle, R.W. Site-specific and stoichiometric conjugation of cationic porphyrins to antiangiogenic monoclonal antibodies. Bioconjug. Chem. 2010, 21, 302-313.

121. Hamblin, M.R.; Del Governatore, M.; Rizvi, I.; Hasan, T. Biodistribution of charged 17.1A photoimmunoconjugates in a murine model of hepatic metastasis of colorectal cancer. Br. J. Cancer 2000, 83, 1544-1551.

122. Duska, L.R.; Hamblin, M.R.; Bamberg, M.P.; Hasan, T. Biodistribution of charged F(ab')2 photoimmunoconjugates in a xenograft model of ovarian cancer. Br. J. Cancer 1997, 75, 837-844.

123. Duska, L.R.; Hamblin, M.R.; Miller, J.L.; Hasan, T. Combination photoimmunotherapy and cisplatin: effects on human ovarian cancer ex vivo. J. Natl. Cancer Inst. 1999, 91, 1557-1563.

124. Hamblin, M.R.; Miller, J.L.; Hasan, T. Effect of charge on the interaction of site-specific photoimmunoconjugates with human ovarian cancer cells. Cancer Res. 1996, 56, 5205-5210.

125. Del Governatore, M.; Hamblin, M.R.; Shea, C.R.; Rizvi, I.; Molpus, K.G.; Tanabe, K.K.; Hasan, T. Experimental photoimmunotherapy of hepatic metastases of colorectal cancer with a $17.1 \mathrm{~A}$ chlorin(e6) immunoconjugate. Cancer Res. 2000, 60, 4200-4205.

126. Molpus, K.L.; Hamblin, M.R.; Rizvi, I.; Hasan, T. Intraperitoneal photoimmunotherapy of ovarian carcinoma xenografts in nude mice using charged photoimmunoconjugates. Gynecol. Oncol. 2000, 76, 397-404.

127. Del Governatore, M.; Hamblin, M.R.; Piccinini, E.E.; Ugolini, G.; Hasan, T. Targeted photodestruction of human colon cancer cells using charged 17.1A chlorin e6 immunoconjugates. Br. J. Cancer 2000, 82, 56-64.

128. Jiang, F.N.; Jiang, S.; Liu, D.; Richter, A.; Levy, J.G. Development of technology for linking photosensitizers to a model monoclonal antibody. J. Immunol. Methods 1990, 134, 139-149.

129. Jiang, F.N.; Allison, B.; Liu, D.; Levy, J.G. Enhanced photodynamic killing of target cells by either monoclonal antibody or low density lipoprotein mediated delivery systems. J. Control Release 1992, 19, 41-58.

130. Jiang, F.N.; Liu, D.J.; Neyndorff, H.; Chester, M.; Jiang, S.Y.; Levy, J.G. Photodynamic killing of human squamous cell carcinoma cells using a monoclonal antibody-photosensitizer conjugate. J. Natl. Cancer Inst. 1991, 83, 1218-1225.

131. Berthiaume, F.; Reiken, S.R.; Toner, M.; Tompkins, R.G.; Yarmush, M.L. Antibody-targeted photolysis of bacteria in vivo. Biotechnology (N.Y.) 1994, 12, 703-706.

132. Strong, L.H.; Berthiaume, F.; Yarmush, M.L. Control of fibroblast populated collagen lattice contraction by antibody targeted photolysis of fibroblasts. Lasers Surg. Med. 1997, 21, 235-247.

133. Thorpe, W.P.; Toner, M.; Ezzell, R.M.; Tompkins, R.G.; Yarmush, M.L. Dynamics of photoinduced cell plasma membrane injury. Biophys. J. 1995, 68, 2198-2206. 
134. Lu, X.M.; Fischman, A.J.; Stevens, E.; Lee, T.T.; Strong, L.; Tompkins, R.G.; Yarmush, M.L. Sn-chlorin e6 antibacterial immunoconjugates. An in vitro and in vivo analysis. J. Immunol. Methods 1992, 156, 85-99.

135. Hasan, T.; Lin, A.; Yarmush, D.; Oseroff, A.; Yarmush, M. Monoclonal antibody-chromophore conjugates as selective phototoxins. J. Control Release 1989, 10, 107-117.

136. Goff, B.A.; Hermanto, U.; Rumbaugh, J.; Blake, J.; Bamberg, M.; Hasan, T. Photoimmunotherapy and biodistribution with an OC125-chlorin immunoconjugate in an in vivo murine ovarian cancer model. Br. J. Cancer 1994, 70, 474-480.

137. Goff, B.A.; Bamberg, M.; Hasan, T. Photoimmunotherapy of human ovarian carcinoma cells ex vivo. Cancer Res. 1991, 51, 4762-4767.

138. Goff, B.A.; Blake, J.; Bamberg, M.P.; Hasan, T. Treatment of ovarian cancer with photodynamic therapy and immunoconjugates in a murine ovarian cancer model. Br. J. Cancer 1996, 74, 1194-1198.

139. Savellano, M.D.; Owusu-Brackett, N.; Son, J.; Ganga, T.; Leung, N.L.; Savellano, D.H. Photodynamic Tumor Eradication With a Novel Targetable Photosensitizer: Strong Vascular Effects and Dependence on Treatment Repetition Versus Potentiation. Photochem. Photobiol. 2012, doi: 10.1111/php.12018.

140. Dumontet, C.; Jordan, M.A. Microtubule-binding agents: A dynamic field of cancer therapeutics. Nat. Rev. Drug Discov. 2010, 9, 790-803.

141. Pèlegrin, A.; Folli, S.; Buchegger, F.; Mach, J.P.; Wagnières, G.; van den Bergh, H. Antibodyfluorescein conjugates for photoimmunodiagnosis of human colon carcinoma in nude mice. Cancer 1991, 67, 2529-2537.

142. Kuimova, M.K.; Bhatti, M.; Deonarain, M.; Yahioglu, G.; Levitt, J.A.; Stamati, I.; Suhling, K.; Phillips, D. Fluorescence characterisation of multiply-loaded anti-HER2 single chain Fv-photosensitizer conjugates suitable for photodynamic therapy. Photochem. Photobiol. Sci. 2007, 6, 933-939.

143. Bhatti, M.; MacRobert, A.; Henderson, B.; Shepherd, P.; Cridland, J.; Wilson, M. Antibodytargeted lethal photosensitization of Porphyromonas gingivalis. Antimicrob. Agents Chemother. 2000, 44, 2615-2618.

144. Stuchinskaya, T.; Moreno, M.; Cook, M.J.; Edwards, D.R.; Russell, D.A. Targeted photodynamic therapy of breast cancer cells using antibody-phthalocyanine-gold nanoparticle conjugates. Photochem. Photobiol. Sci. 2011, 10, 822-831.

145. Bulina, M.E.; Chudakov, D.M.; Britanova, O.V.; Yanushevich, Y.G.; Staroverov, D.B.; Chepurnykh, T.V.; Merzlyak, E.M.; Shkrob, M.A.; Lukyanov, S.; Lukyanov, K.A. A genetically encoded photosensitizer. Nat. Biotechnol. 2005, 24, 95-99.

146. Vegh, R.B.; Solntsev, K.M.; Kuimova, M.K.; Cho, S.; Liang, Y.; Loo, B.L.W.; Tolbert, L.M.; Bommarius, A.S. Reactive oxygen species in photochemistry of the red fluorescent protein "Killer Red". Chem. Commun. (Camb.) 2011, 47, 4887-4889.

147. Serebrovskaya, E.; Stremovsky, O.; Chudakov, D.; Lukyanov, K.; Deyev, S. Genetically encoded immunophotosensitizer. Russ. J. Bioorg. Chem. 2011, 37, 123-129. 
148. Serebrovskaya, E.O.; Edelweiss, E.F.; Stremovskiy, O.A.; Lukyanov, K.A.; Chudakov, D.M.; Deyev, S.M. Targeting cancer cells by using an antireceptor antibody-photosensitizer fusion protein. Proc. Natl. Acad. Sci. USA 2009, 106, 9221-9225.

149. Oseroff, A.R.; Ohuoha, D.; Hasan, T.; Bommer, J.C.; Yarmush, M.L. Antibody-targeted photolysis: Selective photodestruction of human T-cell leukemia cells using monoclonal antibody-chlorin e6 conjugates. Proc. Natl. Acad. Sci. USA 1986, 83, 8744-8748.

150. Yarmush, M.L.; Thorpe, W.P.; Strong, L.; Rakestraw, S.L.; Toner, M.; Tompkins, R.G. Antibody Targeted Photolysis. Crit. Rev. Ther. Drug Carrier Syst. 1993, 10, 197-252.

151. Savellano, M.D.; Hasan, T. Photochemical targeting of epidermal growth factor receptor: A mechanistic study. Clin. Cancer Res. 2005, 11, 1658-1668.

152. Kaspar, M.; Zardi, L.; Neri, D. Fibronectin as target for tumor therapy. Int. J. Cancer 2006, 118, 1331-1339.

153. Pini, A.; Viti, F.; Santucci, A.; Carnemolla, B.; Zardi, L.; Neri, P.; Neri, D. Design and use of a phage display library. Human antibodies with subnanomolar affinity against a marker of angiogenesis eluted from a two-dimensional gel. J. Biol. Chem. 1998, 273, 21769-21776.

154. Stamati, I.; Kuimova, M.K.; Lion, M.; Yahioglu, G.; Phillips, D.; Deonarain, M.P. Novel photosensitisers derived from pyropheophorbide-a: uptake by cells and photodynamic efficiency in vitro. Photochem. Photobiol. Sci. 2010, 9, 1033-1041.

155. Folli, S.; Wagnières, G.; Pèlegrin, A.; Calmes, J.M.; Braichotte, D.; Buchegger, F.; Chalandon, Y.; Hardman, N.; Heusser, C.; Givel, J.C. Immunophotodiagnosis of colon carcinomas in patients injected with fluoresceinated chimeric antibodies against carcinoembryonic antigen. Proc. Natl. Acad. Sci. USA 1992, 89, 7973-7977.

156. Collins, H.A.; Khurana, M.; Moriyama, E.H.; Mariampillai, A.; Dahlstedt, E.; Balaz, M.; Kuimova, M.K.; Drobizhev, M.; Yang, V.X.D.; Phillips, D.; et al. Blood-vessel closure using photosensitizers engineered for two-photon excitation. Nat. Photonics. 2008, 2, 420-424.

157. Khurana, M.; Collins, H.A.; Karotki, A.; Anderson, H.L.; Cramb, D.T.; Wilson, B.C. Quantitative in vitro demonstration of two-photon photodynamic therapy using photofrin and visudyne. Photochem. Photobiol. 2007, 83, 1441-1448.

158. Pawlicki, M.; Collins, H.A.; Denning, R.G.; Anderson, H.L. Two-photon absorption and the design of two-photon dyes. Angew. Chem. Int. Ed. Engl. 2009, 48, 3244-3266.

159. Kuroki, M.; Hachimine, K.; Abe, H.; Shibaguchi, H.; Kuroki, M.; Maekawa, S.-I.; Yanagisawa, J.; Kinugasa, T.; Tanaka, T.; Yamashita, Y. Sonodynamic therapy of cancer using novel sonosensitizers. Anticancer Res. 2007, 27, 3673-3677.

160. Ma, X.; Pan, H.; Yi, J. Combination sonodynamic therapy with immunoadjuvant may be a promising new modality for cancer treatment. Med. Hypotheses 2009, 72, 418-420.

161. Yamaguchi, S.; Kobayashi, H.; Narita, T.; Kanehira, K.; Sonezaki, S.; Kudo, N.; Kubota, Y.; Terasaka, S.; Houkin, K. Sonodynamic therapy using water-dispersed TiO2-polyethylene glycol compound on glioma cells: Comparison of cytotoxic mechanism with photodynamic therapy. Ultrason. Sonochem. 2011, 18, 1197-1204.

162. Huang, X.; Jain, P.K.; El-Sayed, I.H.; El-Sayed, M.A. Plasmonic photothermal therapy (PPTT) using gold nanoparticles. Lasers Med. Sci. 2008, 23, 217-228. 
163. Huang, X.; Qian, W.; El-Sayed, I.H.; El-Sayed, M.A. The potential use of the enhanced nonlinear properties of gold nanospheres in photothermal cancer therapy. Lasers Surg. Med. 2007, 39, 747-753.

164. El-Sayed, I.H.; Huang, X.; El-Sayed, M.A. Selective laser photo-thermal therapy of epithelial carcinoma using anti-EGFR antibody conjugated gold nanoparticles. Cancer Lett. 2006, 239, $129-135$.

165. Liu, Y.; Chen, W.; Wang, S.; Joly, A.G. Investigation of water-soluble X-ray luminescence nanoparticles for photodynamic activation. Appl. Phys. Lett. 2008, 92, 043901-043901-043903.

166. Samia, A.C.S.; Dayal, S.; Burda, C. Quantum dot-based energy transfer: perspectives and potential for applications in photodynamic therapy. Photochem. Photobiol. 2006, 82, 617-625.

167. Juzenas, P.; Chen, W.; Sun, Y.-P.; Coelho, M.A.N.; Generalov, R.; Generalova, N.; Christensen, I.L. Quantum dots and nanoparticles for photodynamic and radiation therapies of cancer. Adv. Drug Deliv. Rev. 2008, 60, 1600-1614.

168. Chen, W.; Zhang, J. Using nanoparticles to enable simultaneous radiation and photodynamic therapies for cancer treatment. J. Nanosci. Nanotechnol. 2006, 6, 1159-1166.

169. Vaidya, A.; Sun, Y.; Feng, Y.; Emerson, L.; Jeong, E.-K.; Lu, Z.-R. Contrast-enhanced MRIguided photodynamic cancer therapy with a pegylated bifunctional polymer conjugate. Pharm. Res. 2008, 25, 2002-2011.

170. Huang, P.; Li, Z.; Lin, J.; Yang, D.; Gao, G.; Xu, C.; Bao, L.; Zhang, C.; Wang, K.; Song, H.; $\mathrm{Hu}, \mathrm{H}$;; Cui, D. Photosensitizer-conjugated magnetic nanoparticles for in vivo simultaneous magnetofluorescent imaging and targeting therapy. Biomaterials 2011, 32, 3447-3458.

171. Detty, M.R. Direct $1270 \mathrm{~nm}$ irradiation as an alternative to photosensitized generation of singlet oxygen to induce cell death. Photochem. Photobiol. 2012, 88, 2-4.

172. Laptev, R.; Nisnevitch, M.; Siboni, G.; Malik, Z.; Firer, M.A. Intracellular chemiluminescence activates targeted photodynamic destruction of leukaemic cells. Br. J. Cancer 2006, 95, 189-196.

173. Embleton, M.L.; Nair, S.P.; Cookson, B.D.; Wilson, M. Antibody-directed photodynamic therapy of methicillin resistant Staphylococcus aureus. Microb. Drug Resist. 2004, 10, 92-97.

174. Berki, T.; Németh, P. Novel method for in vitro depletion of T cells by monoclonal antibodytargeted photosensitization. J. Immunol. Methods 1998, 211, 139-146.

(C) 2013 by the authors; licensee MDPI, Basel, Switzerland. This article is an open access article distributed under the terms and conditions of the Creative Commons Attribution license (http://creativecommons.org/licenses/by/3.0/). 